
DEVELOPMENT REPORT

DESIGN FEATURES OF THE

LIGHT WATER BREEDER REACTOR (LWBR)

WHICH IMPROVE FUEL UTILIZATION

IN LIGHT WATER REACTORS

(LWBR Development Program)

AUGUST 1981

CONTRACT DE-AC11-76PNOOO14

BETTIS ATOMIC POWER LABORATORY WEST MIFFLIN, PENNSYLVANIA

Operated for the U. S. Department of Energy by WESTINGHOUSE ELECTRIC CORPORATION 


\section{DISCLAIMER}

This report was prepared as an account of work sponsored by an agency of the United States Government. Neither the United States Government nor any agency Thereof, nor any of their employees, makes any warranty, express or implied, or assumes any legal liability or responsibility for the accuracy, completeness, or usefulness of any information, apparatus, product, or process disclosed, or represents that its use would not infringe privately owned rights. Reference herein to any specific commercial product, process, or service by trade name, trademark, manufacturer, or otherwise does not necessarily constitute or imply its endorsement, recommendation, or favoring by the United States Government or any agency thereof. The views and opinions of authors expressed herein do not necessarily state or reflect those of the United States Government or any agency thereof. 


\section{DISCLAIMER}

Portions of this document may be illegible in electronic image products. Images are produced from the best available original document. 


\section{DESIGN FEATURES OF THE LIGHT WATER BREEDER REACTOR (LWBR) \\ WHICH IMPROVE FUEL UTILIZATION IN LIGHT WATER REACTORS}

(LWBR Development Program)

H.C. Hecker and L.B. Freeman

Contract No. DE-AC11-76PN00014

Printed in the United States of America

Available from the

National Technical Information Service

U.S. Department of Commerce 5285 Port Royal Road

Springfield, Virginia 22151

NOTE

This document is an interim memorandum prepared primarily for internal reference and does not represent a final expression of the opinion of Westinghouse. When this memorandum is distributed externally, it is with the express understanding that Westinghouse makes no representation as to completeness, accuracy, or usability of information contained therein.

BETTIS ATOMIC POWER LABORATORY WEST MIFFLIN, PENNSYLVANIA $1512 \AA$

Operated for the U.S. Department of Energy by WESTINGHOUSE ELECTRIC CORPORATION

NBI Log \#0319-79/0154L 


\section{NOTICE}

This report was prepared as an account of work sponsored by the United States Government. Neither the United States, nor the United States Department of Energy, nor any of their employees, nor any of their contractors, subcontractors, or their employees, makes any warranty, expressed or implied, or assumes any legal liability or responsibility for the accuracy, completeness or usefulness of any information, apparatus, product or process disclosed, or represents that its use would not infringe privately owned rights. 
FOREWORD

The Shippingport Atomic Power Station located in Shippingport, Pennsylvania was the first large-scale, central-station nuclear power plant in the United States and the first plant of such size in the world operated solely to produce electric power. The development program for the Shippingport plant was started in 1953 to confirm the practical application of nuclear power for large-scale electric power generation. It has provided much of the technology being used for design and operation of the commercial, central-station nuclear power plants now in use.

Subsequent to development and successful operation of the Pressurized Water Reactor in the Atomic Energy Commission (now Department of Energy, DOE) owned reactor plant at the Shippingport Atomic Power Station, the Atomic Energy Commission in 1965 undertook a research and development program to design and build a Light Water Breeder Reactor core for operation in the Shippingport Station.

The objective of the Light Water Breeder Reactor (LWBR) program has been to develop a technology that would significantly improve the utilization of the nation's nuclear fuel resources employing the well-established water reactor technology. To achieve this objective, work has been directed toward analysis, design, component tests, and fabrication of a water-cooled, thorium oxideuranium oxide fuel cycle breeder reactor for installation and operation at the Shippingport Station. The LWBR core started operation in the Shippingport Station in the Fall of 1977 and is expected to be operated for about 4 to 5 years or more. At the end of this period, the core will be removed and the spent fuel shipped to the Naval Reactors Expended Core Facility for a detailed examination to verify core performance including an evaluation of breeding characteristics.

In 1976, with fabrication of the Shippingport LWBK cure nearing completion, the Energy Research and Development Administration, now DOE, estabi ished the Advanced Water Breeder Applications (AWBA) program to develop and disseminate technical information which would assist U.S. industry in evaluating the LWBR concept for commercial-scale applications. The program is exploring some of the problems that would be faced by industry in adapting technology confirmed in the LWBR program. Information being developed includes concepts for commercialscale prebreeder cores which would produce uranium-233 for 1 ight water breeder cores while producing electric power, improvements for breeder cores based on the technology developed to fabricate and operate the Shippingport LWBR core, and other information and technology to aid in evaluating commercial-scale application of the LWBR concept.

Al1 three development programs (Pressurized Water Reactor, Light Water Breeder Reactor, and Advanced Water Breeder Applications) are under the technical direction of the Office of the Deputy Assistant Secretary for Naval Reactors of DOE. They have the goal of developing practical improvements in the utilization of nuclear fuel resources for generation of electrical energy using water-cooled nuclear reactors.

Technical information developed under the Shippingport, LWBR, and AWBA programs has been and will continue to be published in technical memoranda, one of which is this present report. 
INTENT IONALLY BLANK

*

.

,

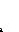


I. INTRODUCTION 1

A. Purpose and Scope 1

B. How is it Possible to Breed in a Light Water Reactor? 2

C. The LWBR Core Concept and Its Application in the Electric Power Industry

D. Summary and Extensions of the LWBR Design 10

II. THE URANIUM-233 AND THORIUM FUEL SYSTEM 11

A. Basis for Anticipated Benefits in Fuel Utilization 11

B. Conversion Ratio and Fissile Inventory Ratio 18

III. ASPECTS OF THE LWBR WHICH IMPROVE NEUTRON ECONOMY 26

A. Movable Fuel Control with a Seed-Blanket Module 29

B. Use of Peripheral Reflector Regions 36

C. Low Hafnium Zirconium Alloy for Fuel Element Cladding and Structurals 38

D. Use of Close Fuel Rod Spacing 39

E. Fuel Rod Support Grid System 40

IV. FUTURE IMPROVEMENTS IN NEUTRON CONSERVATIION TECHNOLOGY

A. Further Development of Movable Fuel Control 42

B. Use of Zircal oy Rod Support Grids 43

C. Fuel Element Design Modifications 44

D. Use of Fuel Management 45

V. CONCLUSIONS 46

ACKNOWLEDGMENTS 46

REFERENCES 


\section{List of Figures}

Figure No. Title

1

Neutron Yield per Neutron Absorbed, $\eta$ versus Energy of Neutron Absorbed

Relative Abundance of Nuclear Fuel in the Earth's Crust

Al ternative Use of Uranium-235 Fission Neutrons in Light Water Reactors

Neutron Yield per Neutron Absorbed, Typical Light Water Reactor Values for Alternate Fissile Fuels

Nuclear Fuel Transmutation

6

Fissile Fuel Reproduction in a Typical Light Water Breeder Reactor Concept

Conversion Ratio versus Water Content at Beginning of Core Life

Fissile Fuel Production Efficiency versus

Relative Initial Uranium-235 Inventory

9

10

Fissile Inventory Ratio versus Relative Fuel Inventory

Uranium Ore Demand versus Time in Water Cooled Reactors

Energy Potential Comparison

Losses to LWBR Conversion Ratio During Core Life

LWBR Cross Section and Module Identification

14

LWBR Movable Fuel Control

R-Z Schematic of An LWBR Module

Neutron Absorption in Axial $\mathrm{H}_{2} \mathrm{O}$ and Structure

Neutron Absorption External to the Twelve Central Modules in the LWBR Core 
This report surveys reactor core design features of the Light Water Breeder Reactor which make possible improved fuel utilization in light water reactor systems and breeding with the uraniumthorium fuel cycle. The impact of developing the uranium-thorium fuel cycle on utilization of nuclear fuel resources is discussed. The specific core design features related to improved fuel utilization and breeding which have been implemented in the Shippingport LWBR core are presented. These design features include a seedblanket module with movable fuel for reactivity control, radial and axial reflector regions, low hafnium Zircaloy for fuel element cladding and structurals, and a closely spaced fuel rod 1attice. Also included is a discussion of several design modifications which could further improve fuel utilization in future light water reactor systems. These include further development of movable fuel control, use of Zircaloy fuel rod support grids, and fuel element design modifications.

DESIGN FEATURES OF THE LIGHT WATER BREEDER REACTOR (LWBR) WHICH IMPROVE FUEL UTILIZATION IN LIGHT WATER REACTORS

\author{
(LWBR Development Program) \\ H.C. Hecker and L.B. Freeman
}

I. INTRODUCTION

\title{
A. Purpose and Scope
}

The purpose of the Light Water Breeder Reactor (LWBR) program is to develop the technology to confirm that breeding* can be achieved in light water reactors, thereby improving significantly the utilization of nuclear fuel resources compared to present types of light water nuclear reactors.

\footnotetext{
*Breeding means producing more fissile fuel in the nuclear reactor than is consumed.
} 
Starting with development work on the Pressurized Water Reactor (PWR Core 1) in 1953, the Office of the Deputy Assistant Secretary for Naval Reactors of the Department of Energy has conducted an ongoing program to develop the technology for improving utilization of nuclear fuel resources in water-cooled reactors. This led to the development of two reactors which operated successfully in the Shippingport Atomic Power Station, PWR Core 1 and PWR Core 2. A third reactor, the Light Water Breeder Reactor (LWBR), is currently operating in the Shippingport plant (Reference 1). The LWBR core is a seed-blanket design as were the earlier PWR cores, but the LWBR uses uranium-233 as the primary fissile material and has additional features which lead to more efficient utilization of neutrons.

The purposes of this report are to summarize the reasons why breeding can be achieved in a light water reactor using the uranium-233/thorium fuel system and to present a survey of the core design features which have been implemented in the Shippingport LWBR core to enhance fuel utilization. Based on the experience gained in the LWBR program and its predecessors, several potential design modifications are also presented which could further improve fuel utilization in future light water reactor systems. Development of these concepts is continuing at the Bettis and Knolls Laboratories in the Advanced Water Breeder Applications (AWBA) program.

\section{B. How is it Possible to Breed in a Light Water Reactor?}

The absorption of one neutron by the nucleus of an atom of thorium can convert it to an atom of uranium-233. By placing thorium in a nuclear reactor with enough uranium-233 (to get the energy needed from fission for the power demand of the plant), the thorium atoms will be exposed to the neutrons produced by the fissions of the uranium atoms. Many of the thorium atoms will absorb a neutron and be converted into uranium-233 atoms. If the amount of uranium-233 remaining after reactor operation is larger than the amount of uranium-233 initially loaded into the core, then the reactor is a breeder reactor. 
The accepted view in the early $1950^{\prime}$ 's was that breeding was not feasible in a light water reactor. The LWBR Program has developed a high level of confidence that breeding is both feasible and practical in pressurized water reactors. Four factors are particularly important to the conclusion that it is practical to breed in a LWBR: (a) more accurate basic nuclear data for uranium-233 showing enhanced breeding in a reactor with low water content (close fuel rod spacing), (b) use of zirconium alloy rather than stainless steel for fuel element cladding and structurals, (c) use of a reactivity control concept that eliminates neutron losses by parasitic absorption in control poisons, and (d) use of large reactors (of the size now being built) which have significantly lower neutron loss by leakage from the reactor than did the plants studied in the $1950^{\prime} \mathrm{s}$. These four items are discussed in greater detail in the following paragraphs.

\section{Fuel Nuclear Properties Necessary to Permit Breeding}

The nuclear parameter most important to breeding is the neutron regeneration factor $(n)$, which is the average number of neutrons produced in fission for each neutron absorbed in fissile fuel. To achieve breeding, this ratio must be greater than 2.0 since maintaining the critical nuclear chain reaction in the reactor takes one of these neutrons for absorption in fissile fuel, leaving $(n-1)$ neutrons to be distributed among the various parasitic losses and the fertile fuel. Unless at least one of these neutrons is captured in fertile fuel to produce new fissile fuel, the total fissile fuel content will decrease as the reactor operates, and breeding will not occur. The parameter $(n-2)$ for a given fuel indicates the margin for parasitic losses in a breeder using that fuel. The value of $n$ is different for each fissile material and, even for a given material, $n$ varjes markedly depending on the average energy level of the neutrons being absorbed in fuel to cause fission. The $n$ for fast neutrons is quite different than that for thermal neutrons.

Only three nuclear fuel materiais are capable of fissioning on a practical basis for the production of electrical energy. These are uranium-235, plutonium-239, and uranium-233. Of these fissile materials, only uranium-235 
is found in nature; the uranium-233 is produced by neutron absorption in thorium; plutonium-239 is produced by neutron absorption in uranium-238.

Early work indicated that $n$ of uranium-235 and plutonium-239 for purely thermal neutrons is only slightly greater than 2.0, and that this quantity decreases as the moderator temperature increases to practical levels required for power reactor operation. Further, there was evidence that the values of $n$ for uranium-235 and plutonium-239 were less than 2.0 for neutrons in the so-called intermediate energy range (between thermal neutrons and fast neutrons). Thus, these early data indicated that breeding with uranium-235 or plutonium-239 would be possible only if a very-high-energy neutron environment could be maintained. That is, they implied that breeding was possible only in fast reactors, which cannot operate with a neutron moderating coolant like ordinary (1ight) water.

On the other hand, uranium-233 was observed to have a value for $n$ of about 2.3 for thermal neutrons. However, it was thought that $n$ dropped to about 2.07 for intermediate energy neutrons, so that while breeding was possible if a thermal neutron spectrum could be maintained, it did not appear practical to breed with light water because there would be too much parasitic neutron loss in water.

Subsequently, more accurate experimental work at Bettis Atomic Powe Laboratory, Knolls Atomic Power Laboratory (KAPL), and Oak Ridge National Laboratory (ORNL) using a number of different experimental techniques has clearly indicated that $n$ of uranium-233 for intermediate neutrons is about 2.13 rather than the previously estimated value of 2.07 (see figure 1 ). Extensive reactor analyses at Bettis - and confirmed at KAPL - have indicated that improved breeding characteristics can be achieved if a thorium/uranium233 reactor is designed with a minimum of water to minimize neutrons "1ost" by capture in water. In such a reactor, a relatively large fraction of the neutrons absorbed in uranium-233 are of intermediate energy, which results in an effective $n$ closer to that for intermediate energy neutrons (2.13) than that for thermal neutrons (2.3). However, an additional effect that was not adequately accounted for in early studies is that as the neutron energy 


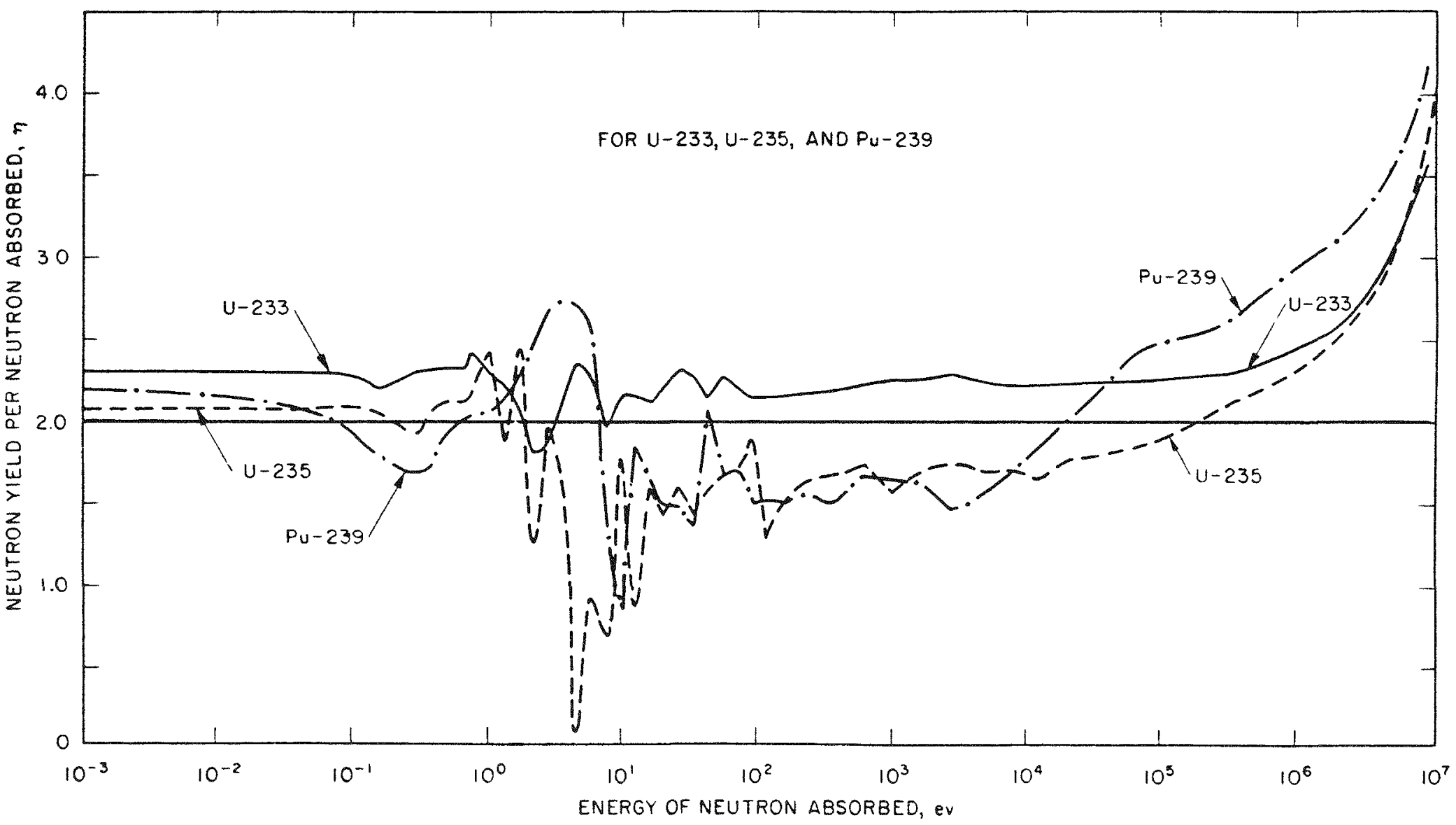

FIGURE 1.

Neutron Yield Per Neutron Absorbed, $\eta$ Versus Energy of Neutron Absorbed 
spectrum is shifted from thermal toward the intermediate energy range, additional neutrons are produced, both by fast fission in thorium and by $(n, 2 n)$ reactions (a reaction where a neutron captured in thorium gives rise to the emission of two neutrons) so that the effective value of $\eta$ is more than 2.26. Furthermore, at this higher energy range, the neutron losses by absorption in water and other parasites are signficantly reduced.

Thus, the refinement of nuclear data for uranium-233 showed a greater potential for breeding in a light water reactor with 10 water content (close fuel rod spacing), and this design approach is one important factor that has led to breeding in the LWBR.

\section{Use of Zirconium Alloy for Fuel Element Cladding and Structurals}

A second crucial factor that was necessary for breeding in a light water reactor relates to cladding material. In the early 1950 's the leading candidate materials for fuel cladding were stainless steel and aluminum. For power reactors, the use of aluminum is not promising because of its poor high-temperature properties. Thus, stainless steel was assumed in most studies. Stainless steel has a significant cross section for capture of thermal and intermediate energy neutrons. It, therefore, acts as a poison, causing many neutrons to be "lost" rather than to be used to produce new fuel and enhance breeding.

Zirconium was not seriously considered as a cladding material in these early studies because of its apparent high neutron absorption and exotic nature. However, ORNL discovered that the neutron poisoning in natural zirconium was due to the 2 to 3 percent of hafnium that was present, and that zirconium itself absorbs relatively few neutrons. The Naval Reactors Program developed practical production processes for removal of hafnium and other impurities, and developed high performance zirconium alloys. These developments introduced the practical use of a highly corrosion-resistant and low neutron absorbing clad material, Zircaloy. 
Use of Zircaloy rather than stainless steel as a cladding and structural material is the second crucial contributor to breeding in a 1 ight water reactor.

3. The Seed-Blanket Concept with the Associated Variable Geometry Reactivity Control Concept

The early studies of breeding in light water reactors did not consider the seed-blanket reactor concept. This concept, originally developed for use in the Shippingport Station reactor core, provides flexibility for separately optimizing the two regions - seed and blanket - to carry out their individual functions. The primary role of the seed is to provide neutrons as efficiently as possible for burning fissile fuel. The primary role of the blanket is to use excess neutrons efficiently in producing new fissile fuel by neutron absorption in fertile fuel. In the LWBR, the seed and blanket have each been optimized to maximize neutron production and minimize neutron 10 ss.

An additional advantage of the seed-blanket concept is that it permits practical use of variable geometry reactivity control. Early studies of the light water breeder demonstrated that neutron losses by absorption in poison control rods, or control features common to other light-water reactors, prohibited breeding. Reactivity of a seed-blanket reactor is dominated by the seed; thus changes in seed geometry can cause reactivity variations. This characteristic made it possible to develop the control concept of a movabie seed, in which all necessary reactivity control is achieved without unnecessary loss of neutrons to poison materials. In effect, reactivity is controlled by adjusting neutron absorption in thorium. Full scale tests of this control system under actual operating conditions have demonstrated its practicality.

Thus use of the seed-blanket concept with the associated variable geometry control is the third contributor to breeding in a light water reactor. 


\section{Low Neutron Leakage}

Neutrons that escape or "leak" out of the reactor are lost, and are not available to produce new fissile fuel. Early studies of breeding showed significant loss of neutrons due to leakage. However, neutron leakage can be minimized in a LWBR in three ways. First, the larger size of today's reactors is a significant aid. Second, the seed-blanket concept provides inherently less leakage because the neutron producing seed is surrounded by the neutron absorbing fertile blanket. Finally, a peripheral reflector region fueled with natural thoria surrounding the entire reactor reduces neutron loss by leakage to less than 0.1 percent for a large LWBR.

Thus the reduction of neutron leakage by using a large seedblanket reactor with a reflector is the fourth factor leading to breeding in a light water reactor.

\section{The LWBR Core Concept and Its Application In The Electric Power Industry}

The LWBR core presently operating in the Shippingport Atomic Power Station is batch loaded; i.e., the whole core was installed at one time and at the end of its reactivity lifetime it will be removed all at once. The fissile content of the core will then be assayed to determine whether it has increased sufficiently to provide for the next core, allowing for fuel reprocessing and refabrication losses. The assay is expected to show that there is sufficient fuel and thus confirm that breeding can be achieved in a light water reactor system.

The notion of utilizing fuel efficiently may be quantified in various ways, such as the energy obtained from the reactor per ton of uranium oxide mined (Reference 2), or the energy obtained from the reactor compared to the total energy available from the fuel in an ideal fuel cycle (section IV). The chief requirements for obtaining high fuel utilization in a nuclear reactor are to maximize the number of neutrons produced per neutron captured in fissile fuel and minimize losses of neutrons to nonproductive capture in 
non-fuel materials; e.g., nonproductive capture includes capture in control poisons or in non-fuel materials inside the reactor or neutron leakage from the core. These requirements, referred to as neutron conservation, are important because each neutron conserved is available for converting a fertile atom such as uranium-238 or thorium-232 to a fissile atom such as plutonium-239 or uranium-233. Neutron conservation extends the time for which a fission chain reaction can be sustained with a given initial amount of fissile fuel and, with sufficient conservation, makes it possible to breed in a light water reactor system.

There are two unique neutron-conserving design features in the LWBR core (Reference 1). The first is the use of a variable geometry concept in lieu of soluble boron or poison control rods to control core reactivity* during power operation. The function of the variable geometry control system is to provide for the capture of excess neutrons in fertile thorium-232 rather than in control poison which consumes about 4 percent of the neutrons in current light water reactor (LWR) systems (Reference 2). Additional neutron conservation is achieved in LWBR by reducing neutron absorption in core structures and the coolant water. The last feature is the use of reflector assemblies around the periphery of the core to prevent the loss of neutrons through leakage. These reflector assemblies have the functions of either capturing leakage neutrons in fertile thorium-232 or scattering them back int the core. The use of reflectors with fertile material eliminates most of thi loss of 4 percent of the available neutrons which occurs in a conventional light water core due to leakage from the periphery to reactor vessel internal structures and water (Reference 2).

To breed in a light water-cooled and moderated core the number of neutrons produced per neutron captured in fissile fuel must be maximized and

*The reactivity of a nuclear reactor core is a measure of its ability to multiply or reproduce neutrons and thus keep the fission chain reaction going. 
this can only be accomplished by basing the fuel cycle on the use of thorium and uranium-233, which is referred to as the thorium fuel cycle. Uranium-233, however, is a fissile fuel that does not occur in nature; thus large scale application of the water-cooled breeder fuel cycle would operate in two phases. In the first phase, called the "prebreeder phase", uranium-235 or another fissile fuel would be used to fuel light water reactors which would also contain thorium. Operation of these reactors would produce fissile uranium-233 from the thorium while providing power for generating electricity. The uranium-233 produced in the prebreeder reactors would be used with thorium to fuel breeder reactors which would produce enough new fissile fuel to replace the fuel used in generating electricity and require no further mining or enrichment of uranium.

\section{Summary and Extensions of the LWBR Design}

The design features of LWBR which improve long term fuel utilization in addition to the use of U-233/thorium fuel, include a seedblanket module with variable geometry for reactivity control, low hafnium Zircaloy for fuel rod cladding and structurals, a closely spaced fuel rod lattice (Reference 1), and radial and axial reflector regions.

The Shippingport LWBR core operates at a lower power density and lower fuel burnup than current LWR systems. Modifications to the core design would be desirable to improve power capability in commercial application of the LWBR concept. However, increasing the power density and fuel burnup tend to reduce the breeding margin. Thus, modifications to the LWBR core design would have to provide for improvements in neutron conservation to offset these reductions. There are modifications which could improve neutron conservation and some of this benefit may be used to improve core performance. The modifications include further development of the neutron conserving control concept, use of Zircaloy fuel rod support grids, and fuel element design changes. As noted in section I.A., development is continuing at Bettis and KAPL as part of the AWBA program. 


\section{THE URANIUM-233 AND THORIUM FUEL SYSTEM}

Selection of the $U-233 /$ thorium fuel cycle for LWBR provides several advantages relative to the U-235/U-238 or plutonium fuel cycles for light water reactors. The primary advantage of the $U-233 /$ thorium cycle in thermal reactors is that the average number of neutrons produced per atom of fissile fuel destroyed by neutron absorption is large enough for $U-233$ to permit breeding in a thermal reactor, whereas for either U-235 or Pu-239 this quantity is too small to permit breeding in a thermal reactor. For neutrons in the very high energy range the Pu-239 neutron yield is largest, and for this reason the uranium-plutonium fuel cycle is usually used in fast reactors.

Similarly, in a thermal breeder thorium müst be used because absorption of a neutron by this fertile material results in production of a new U-233 atom whereas neutron absorption by fertile U-238, the predominant constituent of natural uranium, results in production of a Pu-239 atom. In addition, using thorium as a fertile material in combination with either fissile U-235 or fissile U-233 provides a way to utilize the abundant thorium resources as a source of energy and would permit a long-term reduction in the use of uranium reserves, especially when a breeding cycle is achieved.

The U-233/thorium fuel cycle Is discussed in this section and compared to other fuel cycles with respect to fuel utilization.

\section{A. Basis for Anticipated Benefits in Fuel Utilization}

The only reactor fuels that occur in nature are uranium and thorium. Natural uranium contains $99.3 \%$ fertile uranium-238 and about $0.7 \%$ fissile uranium-235. Thorium occurs only as fertile thorium-232. The relative abundance of these fuels in the earth's crust is illustrated in Figure 2, based on data in reference 3. To date, most reactors designed and built have utilized uranium-235 as the fissile material because it is the only naturally occurring fissile isotope. However, the amount of uranium-235 is quite 1 imited, since it represents only 0.7 percent of naturally occurring uranium. Thus, plans for a nuclear power industry that will be a significant 


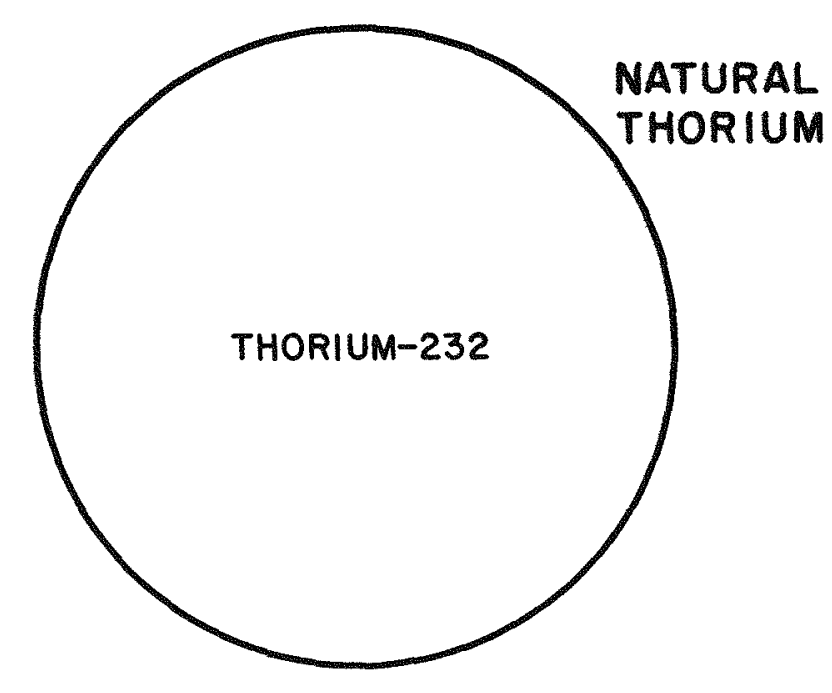

FIGURE 2.

Relative Abundance of Nuclear Fuel in the Earth's Crust 
contributor to total energy resources must make use of the two fertile materials uranium-238 and thorium. Existing nuclear power reactors convert some fertile uranium-238 or thorium into fissile fuel; however, the overall nuclear resource utilization is about 1 percent of the energy potentially available from the mined ore.

Although the fertile materials $U-238$ and Th-232 themselves cannot be used to sustain a nuclear chain reaction, they can be converted into the fissile fuels plutonium-239 and uranium-233, respectively, as illustrated in Figure 3 . The relative fuel conservation benefit of investing uranium-235 fission neutrons in uranium-238 or thorium-232 depends largely on the relative behavior of their characteristic fissile progeny, plutonium-239 and uranium233. The most important measure of behavior is the number of neutrons produced when a neutron is absorbed by an atom of these fissile fuels. In a light water reactor, where most neutrons exist at slow (or thermal) energies, the absorption of one neutron in a uranium-233 atom typically produces more neutrons than the absorption of one neutron in a plutonium-239 atom. This is illustrated in Figure 4.

The principal transmutations that occur when uranium-238 or thorium232 is irradiated by neutrons from fission are illustrated in Figure 5 . There is a strong parallelism between the two fuel systems; however, there are some distinctive differences that favor use of the thorium system in water reactors. Figure 5 illustrates the fact that absorption of a neutron in either thorium-232 or uranium-238 results in production of a new fissile isotope, in each case following two beta emissions. Furthermore, non-fission absorption in these new fissile isotopes (uranium-233 and plutonium-239, respectively) wi11, after another neutron absorption, result in production of a second pair of fissile isotopes, uranium-235 and plutonium-241. The amount of U-235 or Pu-241 produced will be much smaller than the amount of U-233 or Pu-239 produced since most neutron absorptions in these latter materials cause fission. Given the distribution in energy of neutrons in a water-moderated system, more neutrons are produced per atom of uranium-233 destroyed than the number produced per atom of plutonium-239 destroyed. 


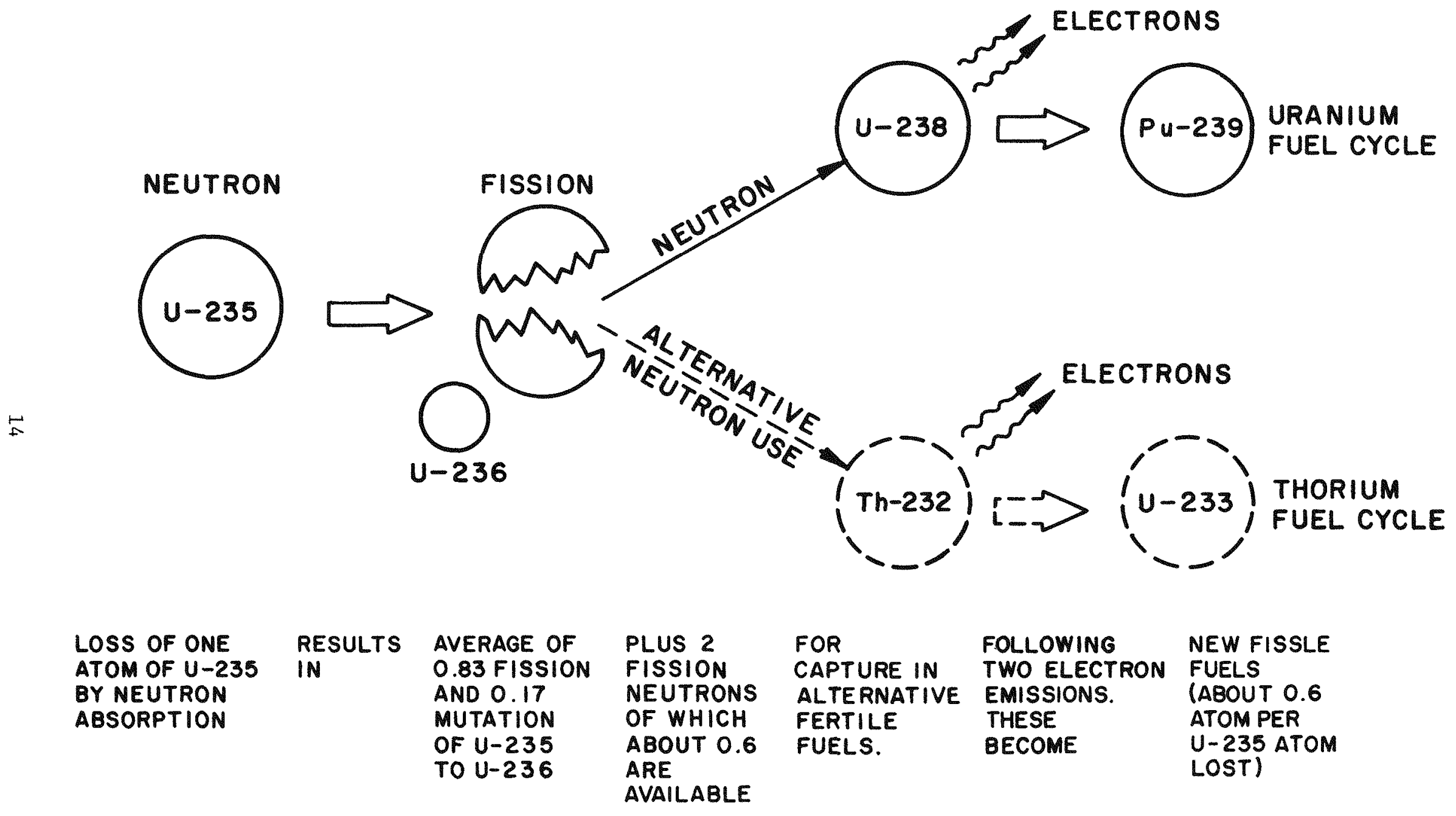

FIGURE 3 . 


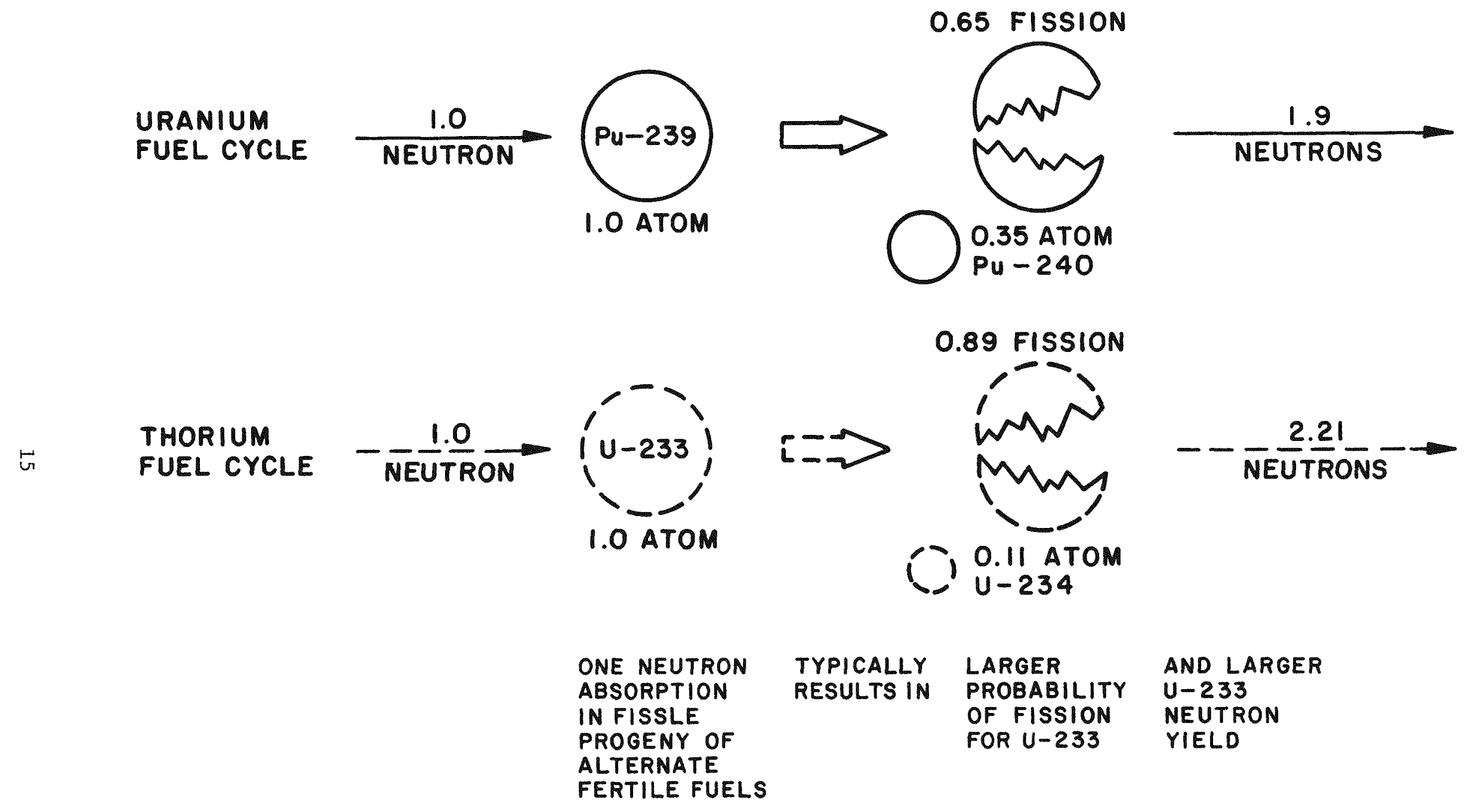

FIGURE 4. 

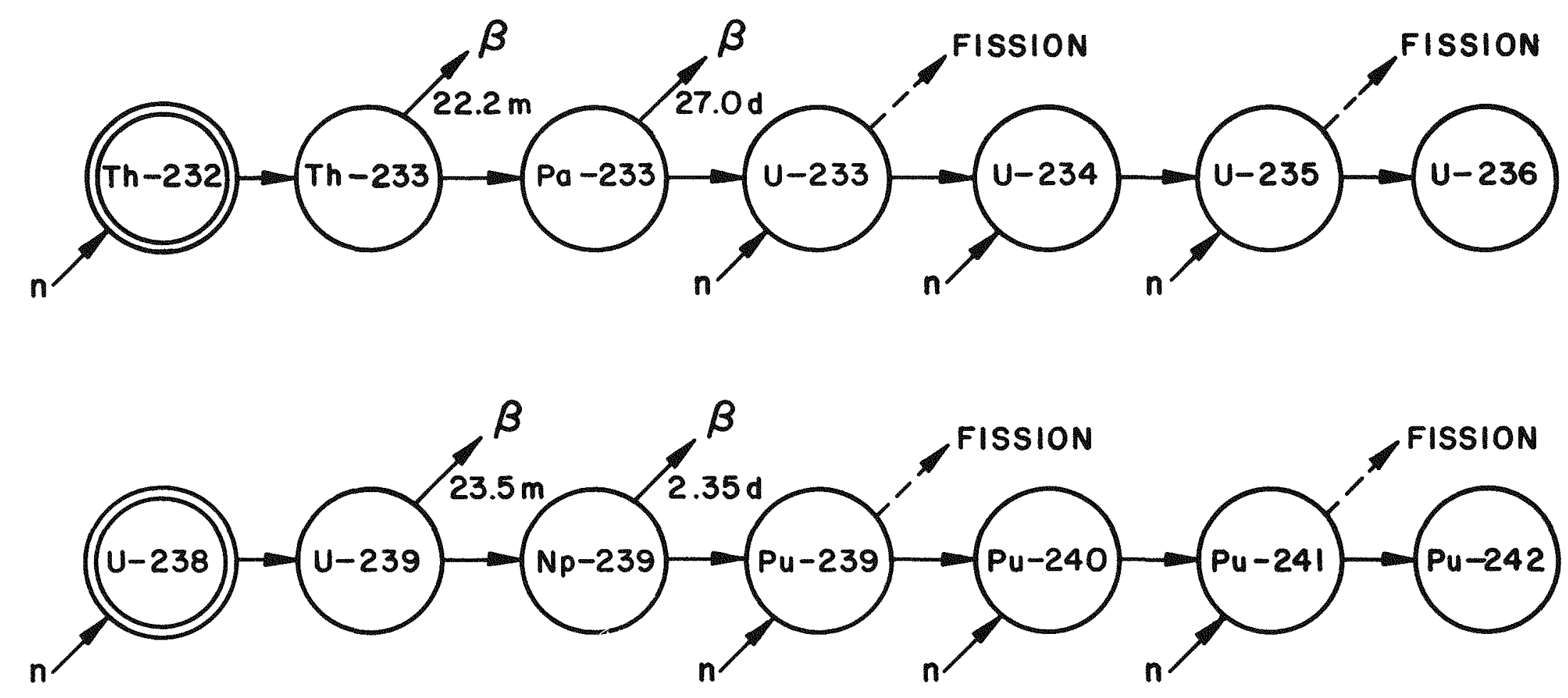

NOTE: ONLY THE TRANSMUTATIONS THAT LEAD TO FISSILE ISOTOPE PRODUCTION ARE SHOWN. OTHER TRANSMUTATIONS SUCH AS PROTACTINIUM-233 GAMMA RAY DECAY AFTER NEUTRON ABSORPTION ARE NOT SHOWN. HOWEVER, THESE ARE INCLUDED IN THE PERFORMANCE CALCULATIONS ON THE CORE CONCEPTS. ANOTHER IMPORTANT DECAY NOT SHOWN IS THAT OF PLUTONIUM-24I WHICH HAS A THIRTEEN YEAR HALF-LIFE AND IS SIGNIFICANT TO BREEDING PERFORMANCE OF URANIUM - PLUTONIUM FUEL.

FIGURE 5 . 
The yield ratio of neutrons produced per atom destroyed for any of the fissile isotopes is not a constant, but rather varies with the energy of the neutron being absorbed, this energy being the determining factor in establishing the relative number of fission and non-fission events. This ratio of neutron yield per neutron absorbed is denoted by eta $(\eta)$. Figure 1 illustrates the value of eta for the three fissile isotopes, uranium-235, uranium-233, and plutonium-239, as a function of energy of the neutron absorbed. At the far right of the figure is the energy with which neutrons are born in fission (average energy approximately $2 \times 10^{6} \mathrm{ev}$ ) and at the far left is the energy of neutrons that have arrived at thermal equilibrium (average energy approximately $5 \times 10^{-2} \mathrm{ev}$ ). The heavier line at a yield of two neutrons per absorption is placed to emphasize the fact that breeding systems must have a yield of at least 2.0 neutrons per absorption to accommodate continuation of the fission chain (one neutron) plus transmutation of a fertile isotope to a new fissile isotope (another neutron). In addition, some margin above 2.0 is required to offset neutron absorption in coolant, structural materials, and fission products, and neutron leakage from the reactor core.

It will be observed that plutonium-239 has a high value of eta in the energy range where neutrons are born in fission; but that eta is less than 2.0 over most of the intermediate and thermal energy ranges. Similarly, uranium233 has an eta greater than 2.0 over nearly the complete energy range. Further, uranium-235 has a significantly lower eta than uranium-233 or (for important parts of the energy range) than plutonium-239.

In any reactor the distribution of energies at which neutrons are absorbed depends upon the volume of coolant in the reactor relative to the volume of fuel and on the moderating properties of the coolant. In the case of present day water reactors, most of the neutron absorptions occur below one electron volt, although a sufficient number occur above this energy level so that breeding with uranium-235 is not a realistic option. Uranium-233 has more favorable properties than either uranium-235 or plutonium-239 in any reactor in which absorption occurs mostly at intermediate or low neutron energies. 
The advantage of uranium-233 in neutron yield per neutron absorbed over most of the thermal and intermediate energy ranges is in fact crucial to the concept of breeding in a light water reactor because the neutron yield is greater than two. After allowing for the use of one neutron to continue the fission chain, there remains more than one neutron for capture in thorium-232 and consequent production of a new uranium-233 atom. If inevitable neutron losses can be minimized, then the system will breed, as illustrated in Figure 6. If the amount of converted fuel, after allowing for unrecoverable fuel during reprocessing and refabrication, still shows a surplus then practical breeding is achieved. Once a breeding fuel cycle has begun using the thoriumuranium-233 fuel system, the only fuel makeup would be fertile thorium; there would be no need for additional fissile fuel makeup. This is the only known approach for significantly increasing the utilization of nuclear fuel in light water reactor plants.

\section{B. Conversion Ratio and Fissile Inventory Ratio}

Another basis for comparison of different fuel cycles is the "conversion ratio", which is defined as the instantaneous rate of production of fissile fuel divided by the rate of destruction of fissile fuel. So long as this ratio exceeds 1.0 the fissile fuel contained in a reactor will increase, and breeding will occur. Figure 7 compares the initial conversion ratio of the three fissile fuels, when used as oxides, as a function of reactor water content*. The right-hand ends of the curves have small water content appropriate to rod lattices in which the rods are touching. The lefthand ends of the scales are for rod lattices with rods spaced further apart than is current commercial practice. The water content of present pressurized water reactor lattices and of an LWBR is indicated. The superior performances of uranium-233 in all water-cooled environments is evident.

\footnotetext{
* Structural content in these calculations was equivalent to the Zircaloy content of LWBR. These curves apply to just-critical infinite lattices of fuel rods, so the conversion ratios do not account for neutron losses to control poisons (if any) or neutron leakage.
} 


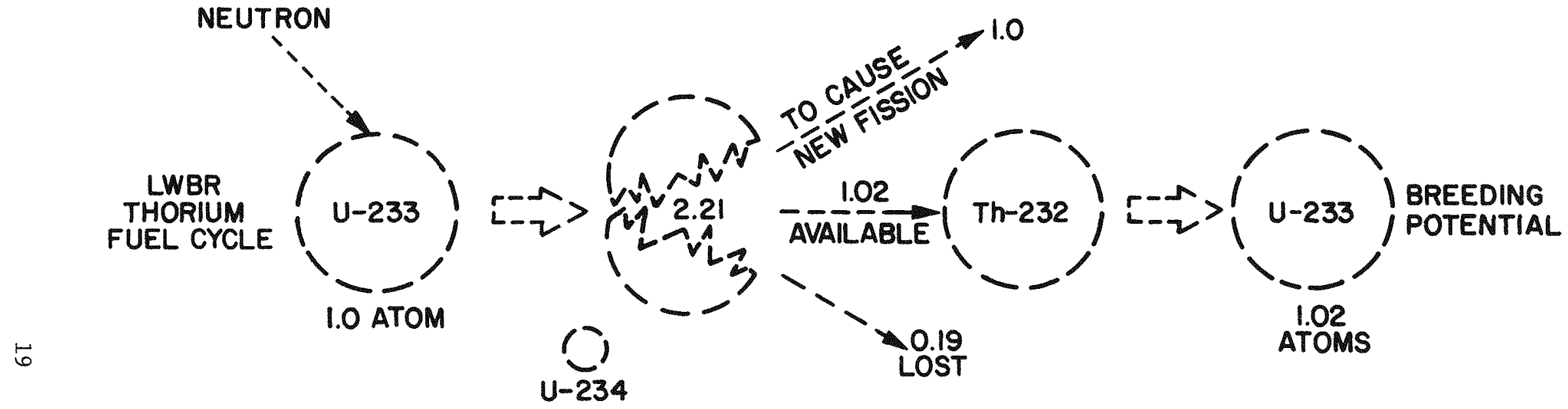

\begin{tabular}{|c|c|c|c|c|c|c|c|}
\hline $\begin{array}{l}\text { LOSS OF ONE } \\
\text { FISSLE ATOM } \\
\text { BY NEUTRON } \\
\text { ABSORPTION }\end{array}$ & $\begin{array}{l}\text { RESULTS } \\
\text { IN }\end{array}$ & $\begin{array}{l}\text { AVERAGE } \\
\text { OF } 0.9 \\
\text { FISSION } \\
\text { AND O.I } \\
\text { MUTATION } \\
\text { OF U-233 } \\
\text { TO U-234 }\end{array}$ & $\begin{array}{l}\text { PLUS } \\
2.21 \\
\text { FISSION } \\
\text { NEUTRONS } \\
\text { OF WHICH }\end{array}$ & $\begin{array}{l}1.02 \\
\text { EXCESS } \\
\text { NEUTRONS } \\
\text { ARE } \\
\text { AVAILABLE }\end{array}$ & $\begin{array}{l}\text { FOR } \\
\text { CAPTURE } \\
\text { IN } \\
\text { FERTILE } \\
\text { FUEL }\end{array}$ & $\begin{array}{l}\text { WHICH } \\
\text { DEPENDING } \\
\text { ON } \\
\text { NEUTRON } \\
\text { LOSSES } \\
\text { RESULTS } \\
\text { IN A }\end{array}$ & $\begin{array}{l}\text { POTENTIAL } \\
\text { NET GAIN } \\
\text { OF FISSILE } \\
\text { FUEL IN } \\
\text { THORIUM } \\
\text { CYCLE }\end{array}$ \\
\hline
\end{tabular}




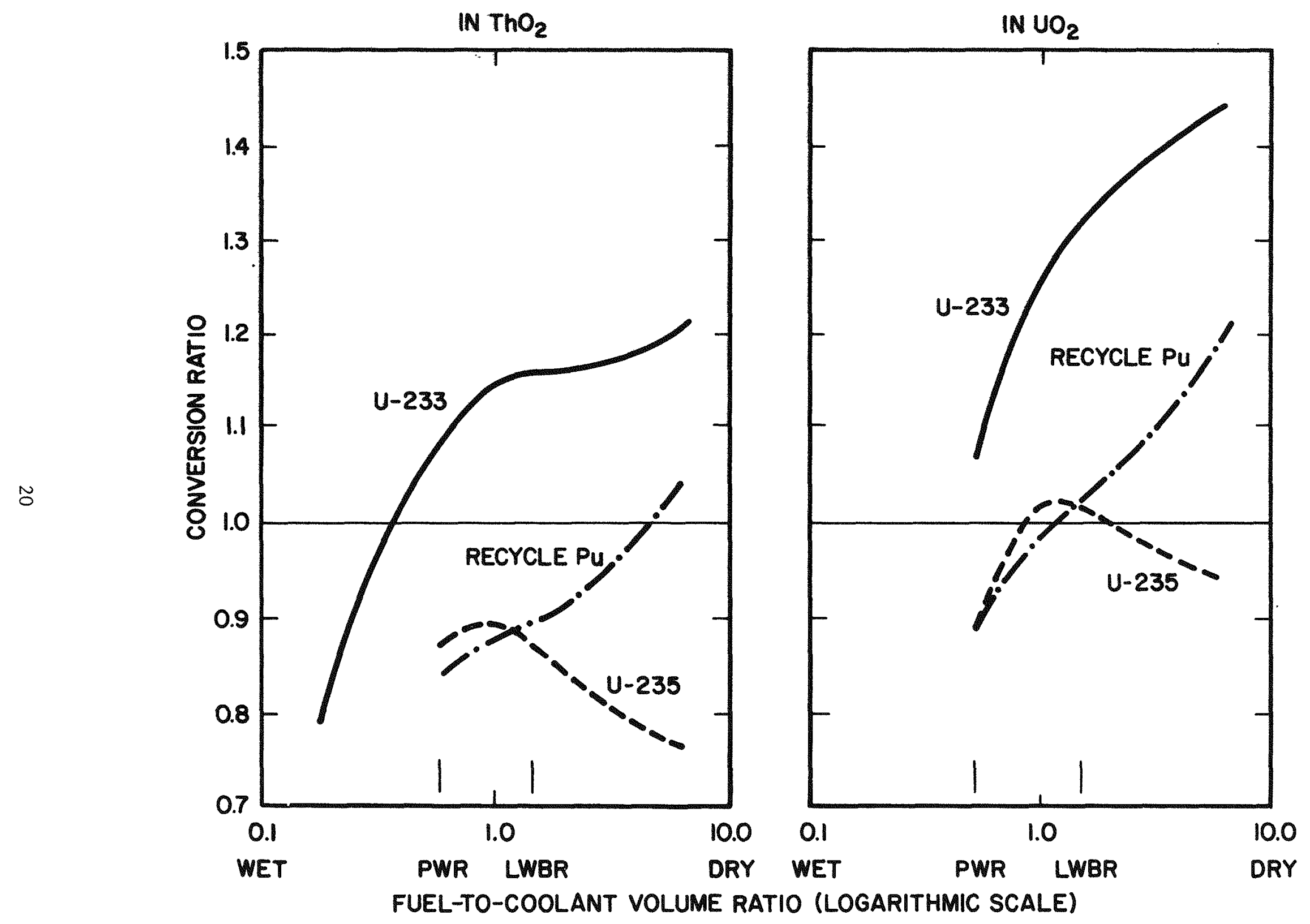

FIGURE 7.

Conversion Ratio Versus Water Content at Beginning of Core Life

For Just Critical Infinite Lattices (No Control Poison or Leakage) 
Consider two alternative uses of available uranium-235 resources, one being in a mixture with fertile uranium-238 as in conventional light water reactors and the other being in a mixture with thorium. One important consequence of the superior uranium-233 conversion property relates to $U-233$ being efficiently produced by absorption in thorium of neutrons from uranium235 fission. As uranium-233 is produced, some of the uranium-233 will in turn be fissioned to produce more uranium-233. Thus, while the initial conversion ratio of uranium-235 in thorium-232 is lower than the initial conversion ratio of uranium-235 in uranium-238 as indicated in Figure 7, the net outcome of these alternative uses of uranium-235 is that more uranium-233 is produced from thorium-232 than plutonium from uranium-238. This is demonstrated in Figure 8 which shows the fissile fuel produced per atom of uranium-235 destroyed as a function of the initial uranium-235 inventory required to obtain 30,000 MWD/MT* fuel lifetime, assuming neutron economic reactivity control such as with variable geometry.

While uranium-233 production is greater than fissile plutonium production per unit of naturally occurring uranium-235 destroyed, in neither case is the amount of fisstie fuel produced as much as the amount of uranium-235 destroyed. When the uranium-233 or plutonium is extracted from the spent fuel and used in a replacement reactor, high fissile fuel reproduction occurs, and the thorium/uranium-233 system has the potential for full replacement of fissile fuel consumed. That is, the ratio of end-of-life fissile fuel content to initial fissile fuel content (Fissile Inventory Ratio or FIR) can be made greater than 1.0 and the system is said to breed. The potential performance of uranium-233 in thorium-232 and of plutonium in uranium-238 is illustrated for light water reactors in Figure $9 * *$.

* Megawatt days per metric ton (MWD/MT). A 30,000 MWD/MT 1ifetime is consistent with current commercial practice.

** Calculations for both systems used the same idealized neutron economic control system, uniform $100 \mathrm{kw}$ per liter power density, and no neutron leakage. The mix of plutonium isotopes assumed was that typical of present pressurized water reactor production. For the Shippingport LWBR, fuel element irradiation wi11 be shorter than present commercial practice. 


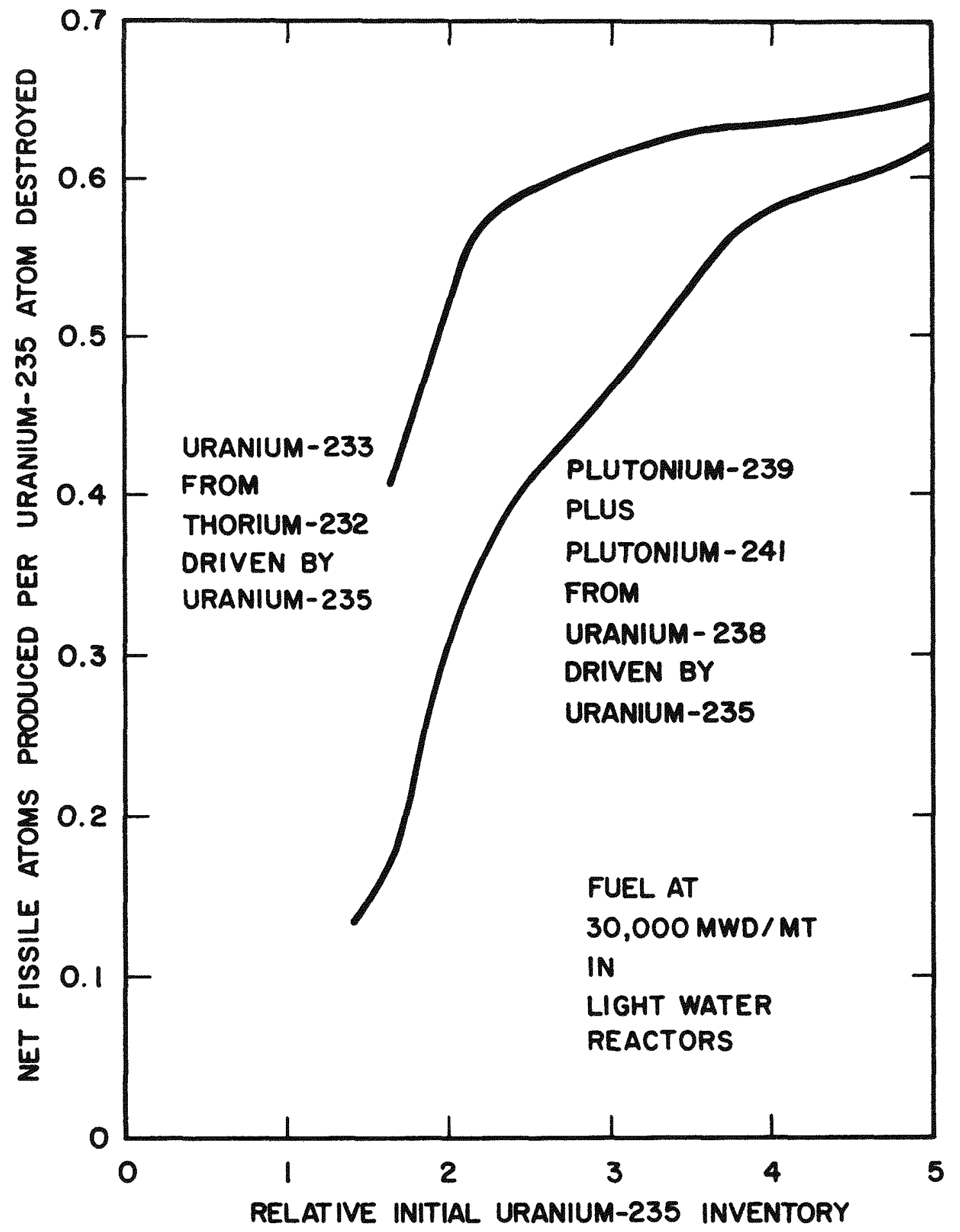

FIGURE 8 .

Fissile Fuel Production Efficiency Versus Relative Initial

Uranium-235 Inventory Assuming Neutron Economic Reactivity Control 


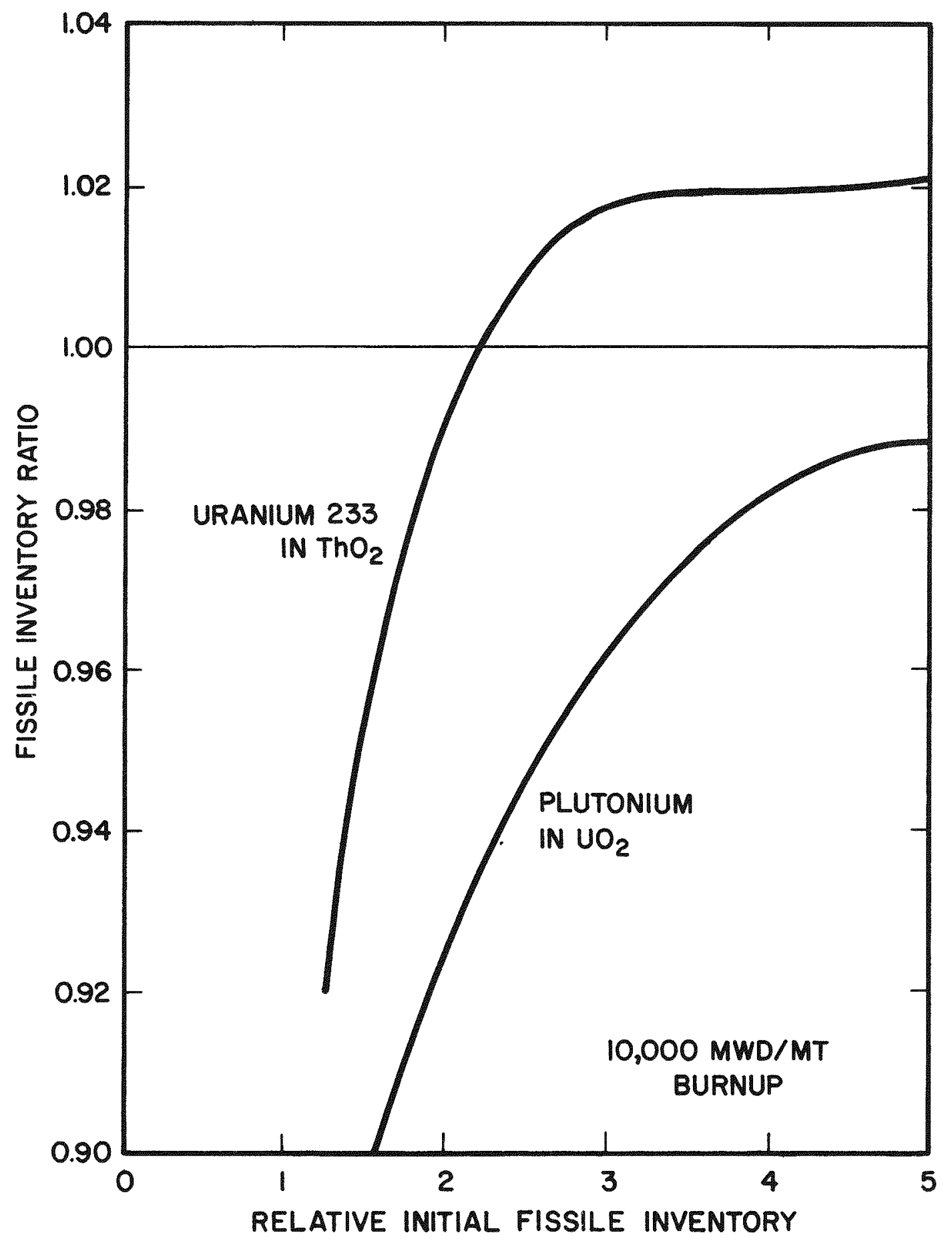

FIGURE 9.

Fissile Inventory Ratio Versus Relative Fissile Inventory Assuming Neutron Economic Reactivity Control 
If the fissile fuel at end of life is less than the amount needed for a subsequent cycle, the differences must ultimately be made up by uranium-235 taken from natural uranium. Current enrichment technology can remove about 0.5 of the $0.7 \% \mathrm{U}-235$ in natural uranium, leaving $0.2 \% \mathrm{U}-235$ in the diffusion plant "tails". Therefore, about 200 tons of natural uranium must be mined to produce one ton of additional uranium-235 in enriched uranium. Thus the total amount of nuclear fuel that must be mined to provide makeup for a nonbreeder rises very rapidly if the end-of-life fissile inventory drops below the amount needed for the next core cycle in addition to making allowance for some fuel reprocessing and refabrication losess. In conventional light water reactors with no recycle the makeup is so great that the fuel utilization is less than one percent. That is, less than 1\% of the energy potential of the mined ore is extracted by the reactor system. Recycling the plutonium generated in light water reactors as well as the residual uranium could increase the fuel utilization somewhat, perhaps to about 1\%. Correspondingly, consumption of uranium-235 from uranium ore resources would be necessary in the prebreeder phase of the thorium fuel cycle to produce uranium-233. But in contrast to the uranium cycle, recycle of uranium-233 in Light Water Breeder Reactors with fertile thorium would permit dramatic increases in the utilization of the latent energy in thorium.

A short-term impact of the overall thorium fuel cycle is the need for higher fissile fuel inventories in the prebreeder than are required in current light water reactors. This impact is illustrated in Figure 10, where a comparison is presented of the tons of $\mathrm{U}_{3} \mathrm{O}_{8}$ (uranium oxide) required to support 1000 megawatts electrical capacity either as LWR's or as LWBR systems. As shown, the $U_{3} O_{8}$ requirement for an LWBR system would be higher in early years of operation, when higher core loadings of the prebreeder would be required. The higher prebreeder fissile inventory is due to the lack of a naturally occurring fissile isotope (1ike U-235) in thorium, the closer spacing of the LWBR fuel rods, and the relative cross sections of U-238 and Th-232. In later years, when LWBR-system plants are operating in the breeder mode, the demand for $U_{3} 0_{8}$ and enrichment of uranium would be terminated, while demand for $\mathrm{U}_{3} \mathrm{O}_{8}$ and enrichment of uranium for conventional LWR cores would continue as long as the unit of capacity supported by that reactor is 


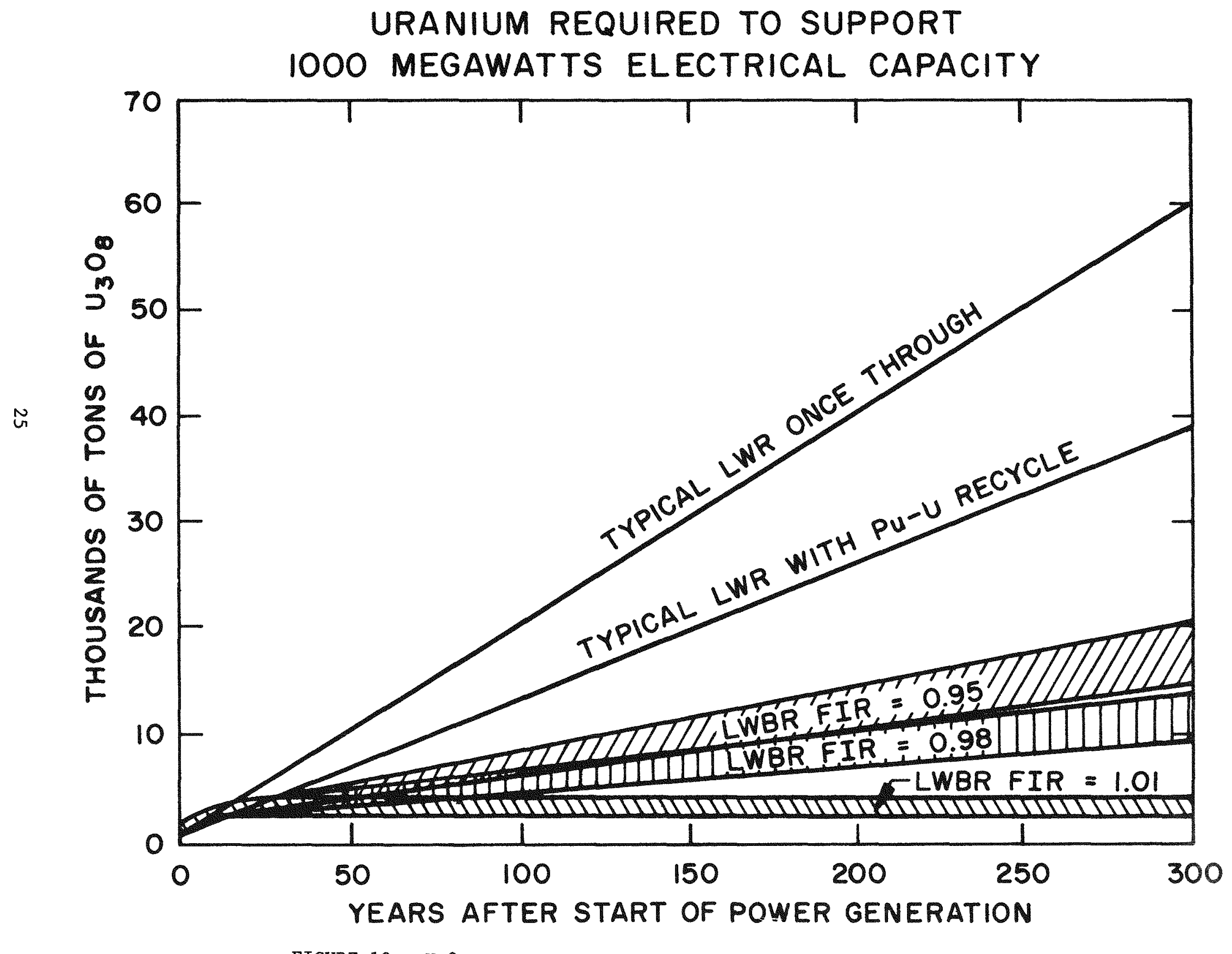

FIGURE 10. $\mathrm{U}_{3} \mathrm{O}_{8}$ Demand Versus Time in Water Cooled Reactors 
operated. For comparison purposes Figure 10 also shows the mining which would be required for an LWBR design for a fissile inventory ration less than one. In this case, there still would be a substantial reduction in mining requirement relative to the conventional LWR, but a continuing supply of uranium would be needed and much lower fuel utilization would be obtained than with LWBR.

A comparison is shown in Figure 11 of the energy potentially obtainable from nuclear fuel resources by use of LWBR type cores to the energy that can be obtained using existing types of light water reactors or from known reserves of fossil fuels. Based on the use of an already well established and successful light water reactor technology and the potential for obtaining over $3 \times 10^{20}$ Btu of energy from an LWBR technology, the development of our thorium resources and use of thorium in light water breeder reactors appears to be an important and attainable alternative for future energy generation.

\section{ASPECTS OF THE LWBR WHICH IMPROVE NEUTRON ECONOMY}

The average neutron yield per neutron absorbed in $U-233$ is approximately 2.25 in the LWBR core. At least 2.0 neutrons are required to provide for continued fissioning and to convert a Th-232 atom into a new U-233 atom; also, some neutron capture in fission products is inevitable. Thus, in order to achieve breeding in the LWBR, neutron conservation methods were designed which would minimize losses of neutrons by capture in non-fuel materials and through leakage from the core.

The reduction in the number of neutrons available to convert a Th- 232 atom to U-233, due to various losses, is shown in Figure 12. The top curve of $n \varepsilon-1$ versus core lifetime includes the neutrons produced per neutron absorbed in fissile fuel, $n$, and a benefit from the small amount of high energy fission in fertile material, $\varepsilon$. The subtraction of one neutron allows for the neutron required to continue the fission chain reaction. Thus $n \varepsilon-1$ gives the net neutrons available for conversion per fissile atom destroyed, before any losses are accounted for. The various losses shown reduce the 


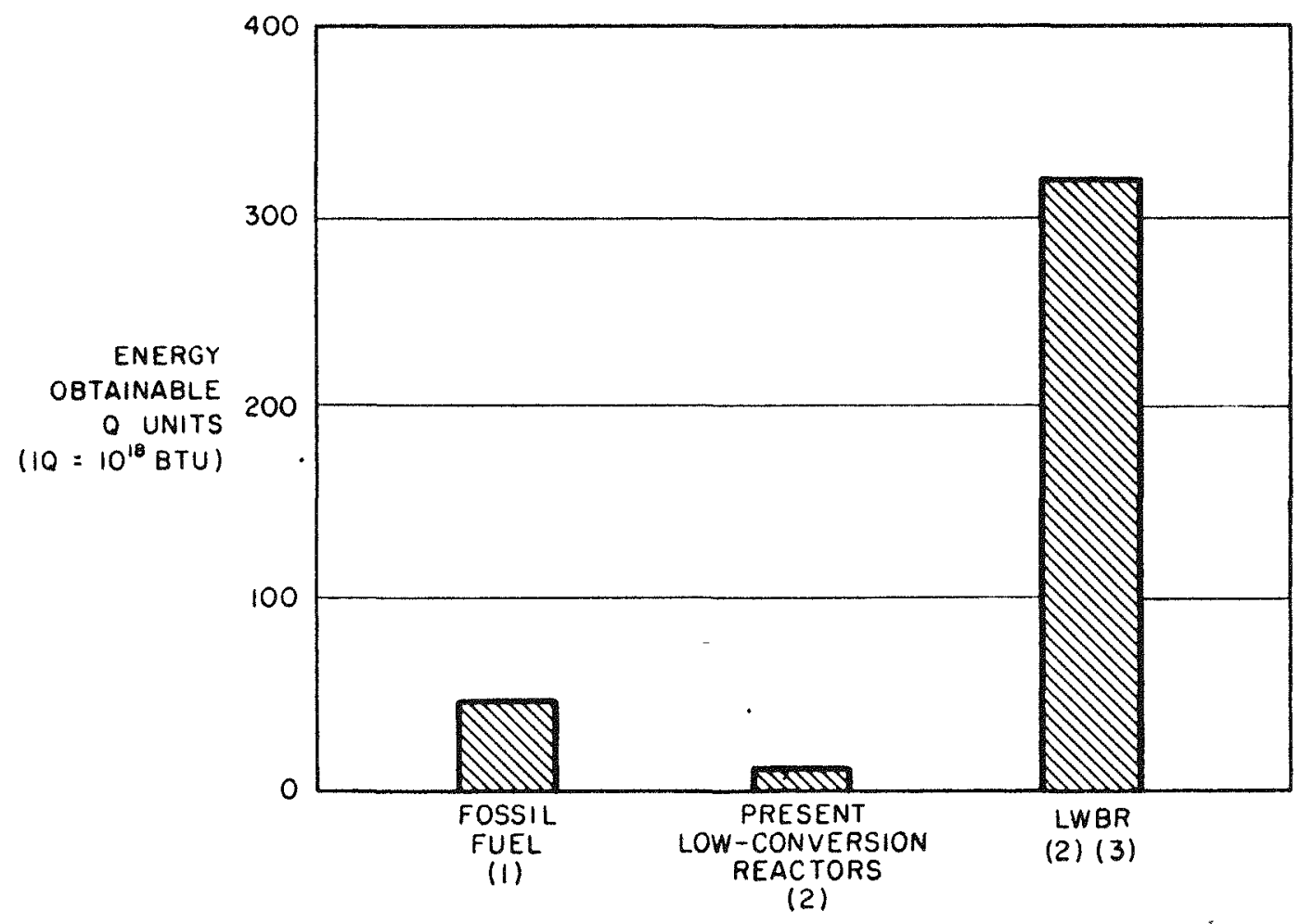

NOTES:

(1) BASED ON U.S. GEOLOGICAL SURVEY PROFESSIONAL PAPER 820, (1973), AND BUREAU OF MINES BULLETIN 650, (1970).

(2) BASED ON WASH-1097, (1969) AND "OUTLOOK FOR URANIUM," J.A. PATTERSON, USAEC 17 TH MINERALS SYMPOSIUM (CASPER, WYOMING), (1974).

(3) BASED ON WASH-1097, (1969), AND WASH-1535 (PROPOSED FINAL), (1974), ASSUMING $1 \%$ FUEL LOSSES DURING RECYCLE OPERATIONS.

FIGURE 11 .

Energy Potential Comparison 


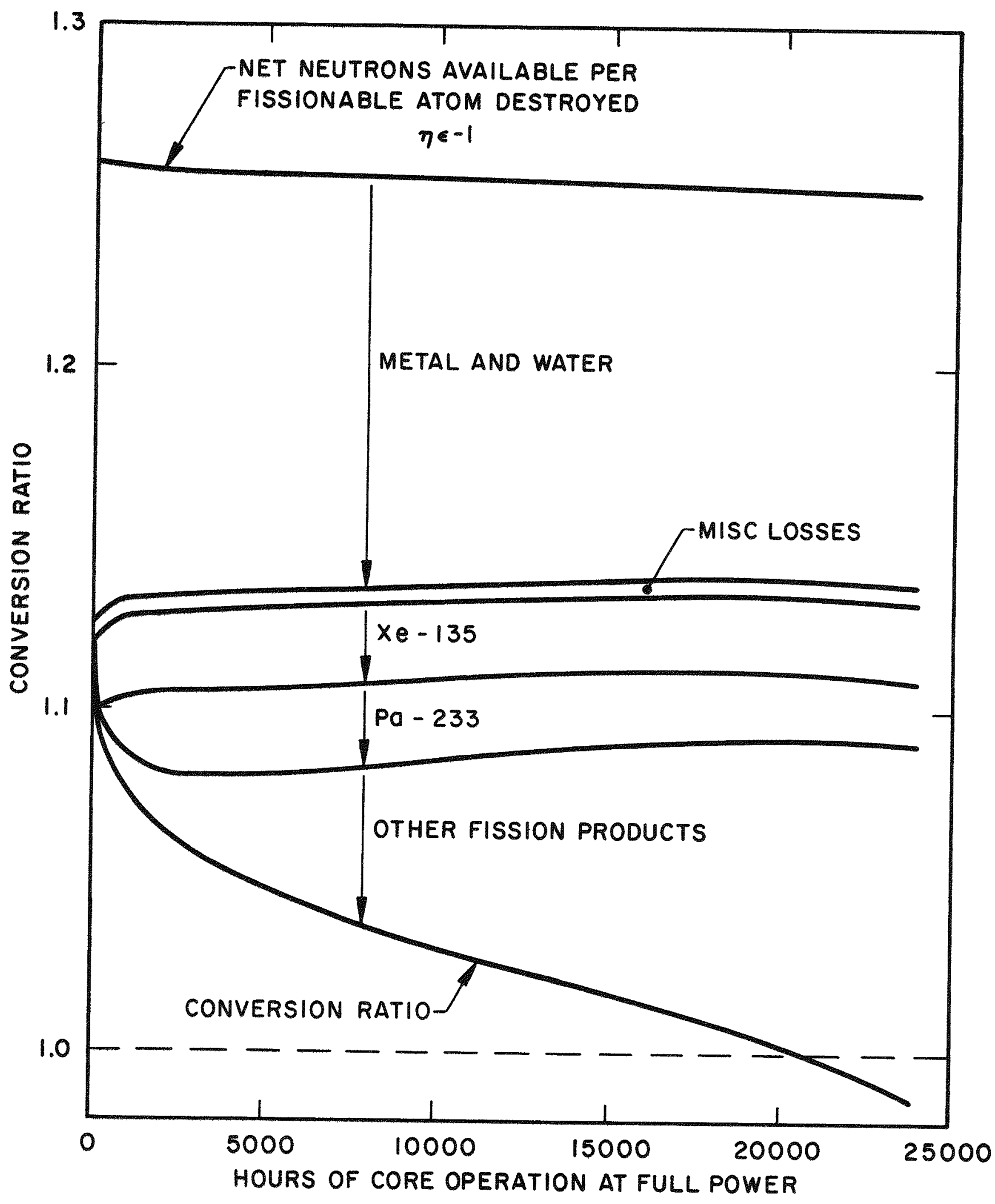

FIGURE 12.

Losses to LWBR Conversion Ratio During Core Life 
availability of neutrons for conversion. Leakage of neutrons beyond the thorium reflector regions which surround the core proper is counted in "Metal and Water" in Figure 12; but for an LWBR this would be a small part of the total loss of neutrons to absorption in water and structure in the core. Finally, the number of fertile atoms converted to fissile atoms, per fissile atom destroyed, is shown as the conversion ratio. As long as the conversion ratio is greater than unity the fissile content in the core increases.

There are two major neutron conserving design features in the LWBR. The first is the use of variable geometry fuel assemblies to control reactivity in lieu of using control poisons such as soluble boron or control rods. The function of the variable geometry control system is to provide for the capture of excess neutrons (which in most reactors would be captured in control poisons) in fertile material (Th-232). The second feature is the use of thorium reflector regions around the periphery of the core to prevent loss of neutrons through leakage.

A comprehensive description of the Light Water Breeder Reactor (LWBR), which is operating in the Shippingport Atomic Power Station, is given in Reference 1. Several features of the LWBR design which improve fuel utilization relative to current Light Water Reactor (LWR) designs are discussed in this section. The cumulative neutron economy resulting from these design features is expected to result in breeding in the Shippingport LWBR. A best estimate calculated fissile inventory ratio in the range 1.013 to 1.016 after three years of operation is given in Reference 4 , where the 1.3 to 1.6 percent breeding margin range is dependent on operational power level variations relative to continuous operation at 100 percent of rated power.

\section{A. Movable Fuel Control with a Seed-Blanket Module}

Control poisons consume about 4 percent of the neutrons in current LWR systems (Reference 2). Use of control rods or soluble boron control was completely 
eliminated in the Shippingport LWBR for normal operating conditions* by design and development of a variable geometry control system. A comprehensive description of the seed-blanket module design and dimensions for the LWBR are given in Reference 1 and the magnitudes of reactivity control and shutdown margin are presented in Reference 4. Only a summary of the movable fuel control concept and its application in the LWBR are presented here.

A cross section of the LWBR core is shown in Figure 13. There are 12 seed regions, each surrounded by a (standard or power flattened) blanket region. These 12 modules are all enclosed by the reflector region. The Roman numerals identify the type of module depending on the shape and the type of blanket. Core reactivity control is achieved by varying the geometric relationship between each movable fuel seed assembly and the stationary annular blanket assembly which surrounds it; this concept is shown in Figure 14. For LWBR operation, this reactivity control is achieved by uniformly positioning the 12 movable seed fuel assemblies in a bank using individual control drive mechanisms.

Changing the axial position of the seed assembly relative to the blanket assembly changes the relative amounts of neutron absorptions in the fissile (uranium-233) and fertile (thorium) fuel materials for the following reasons. The LWBR nuclear design is such that the seed has a higher U-233 concentration than the blanket and therefore acts as a source of excess neutrons which are captured in the blanket. Reactivity is controlled by varying the leakage of neutrons from the seed regions into the blanket regions. The design arrangement of fissionable uranium-233 and thorium, shown in Figure 15, is such that when the central region (the seed) of a fuel module is lowered, the U-233 bearing material at the bottom of the seed loses some of its effectiveness as a source of neutrons because it is farther from the blanket. Similarly, U-233 bearing material at the top of the blanket loses some of its effectiveness. The regions which initially have only thorium and no U-233 (thoria steps) come closer together which enhances their importance in absorbing neutrons and slowing the chain reaction. Thus, the thoria steps

* A chemical shutdown system is provided for the addition of concentrated soluble boron to provide a backup shutdown system in the unlikely event of the normal variable geometry control system failing to function. However, the core would only be operated with the variable geometry system controlling. 


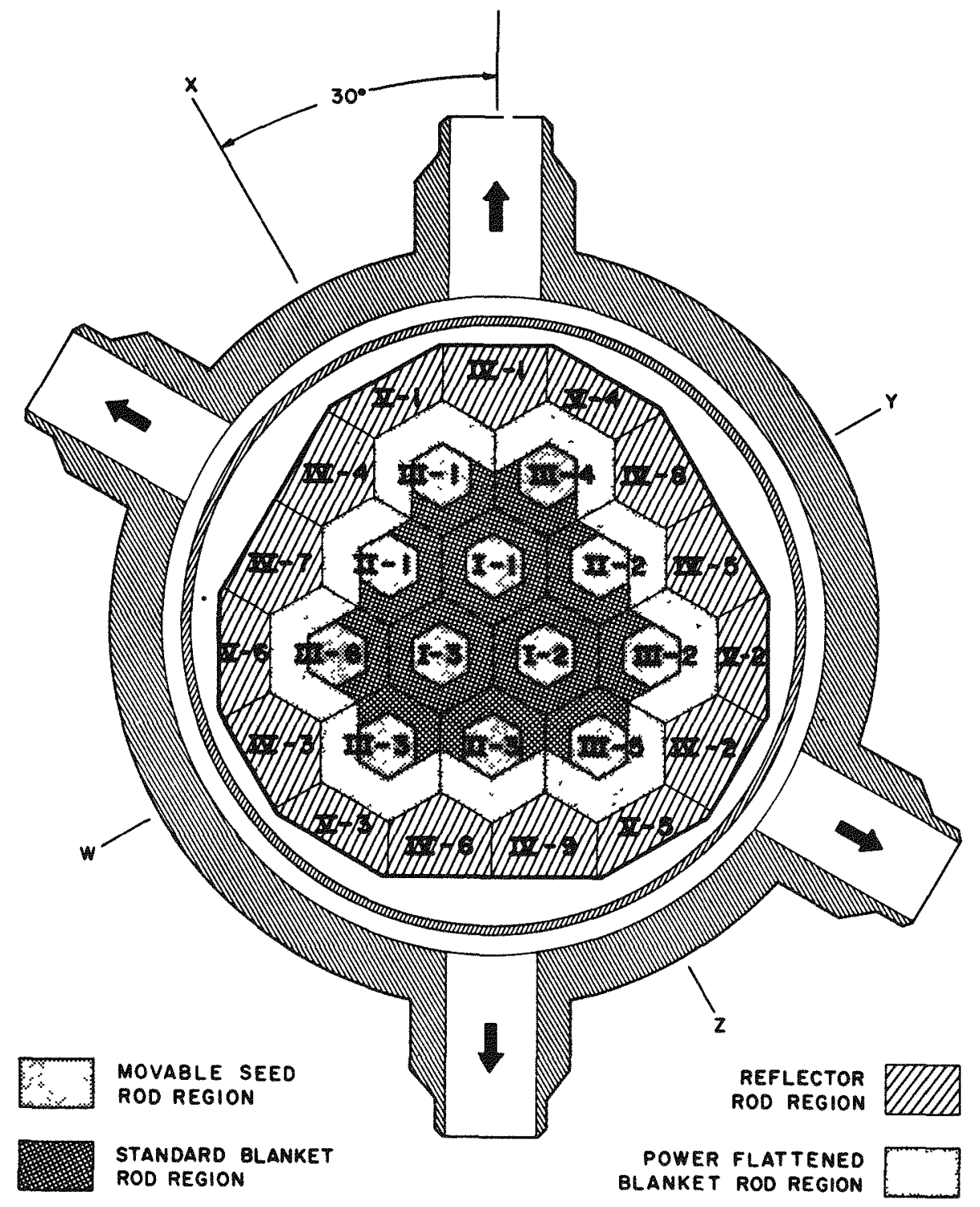

FIGURE 13.

LWBR Cross Section and Module Identification 


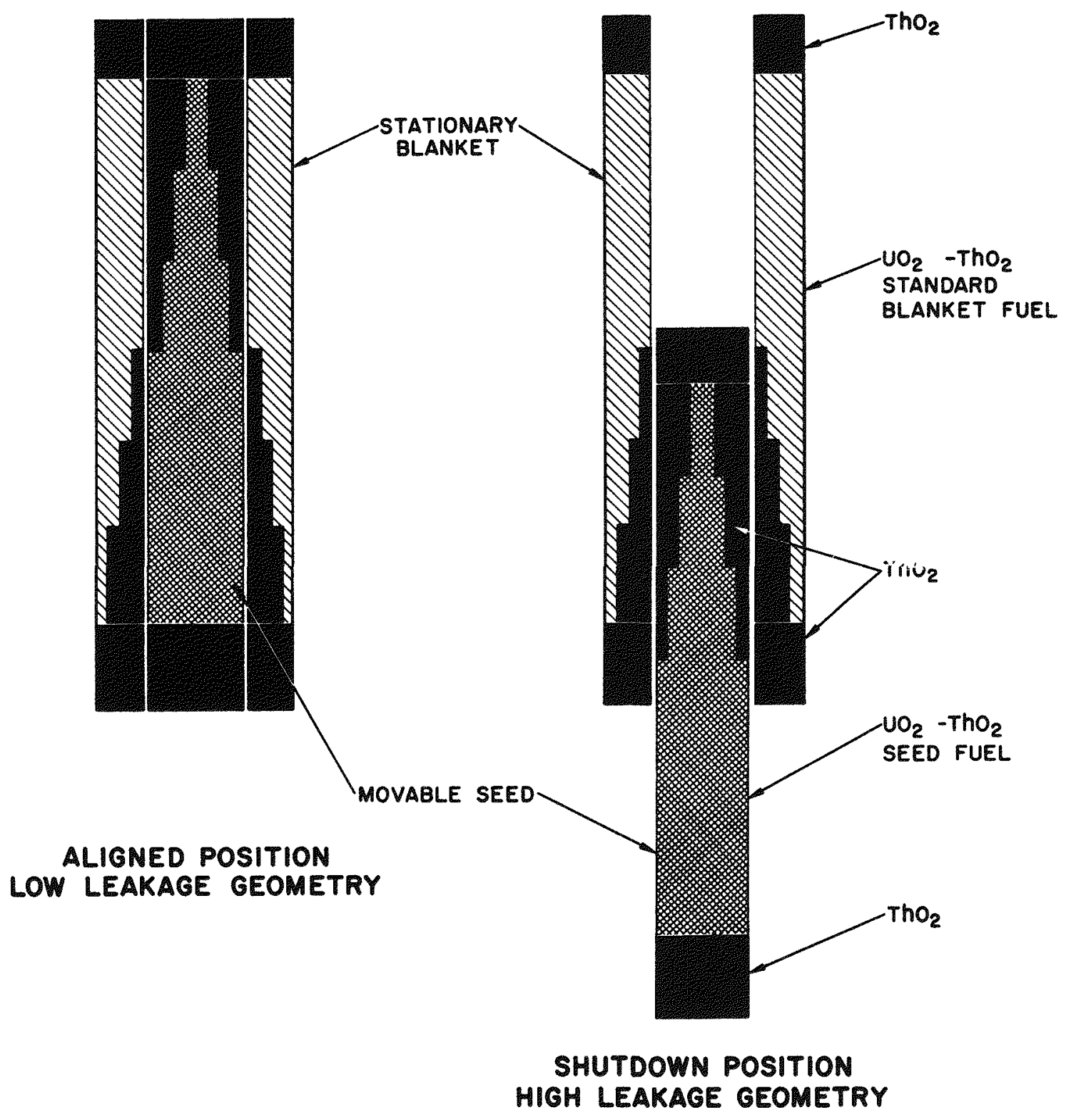

FIGURE 14.

LWBR Variable Geometry Control 


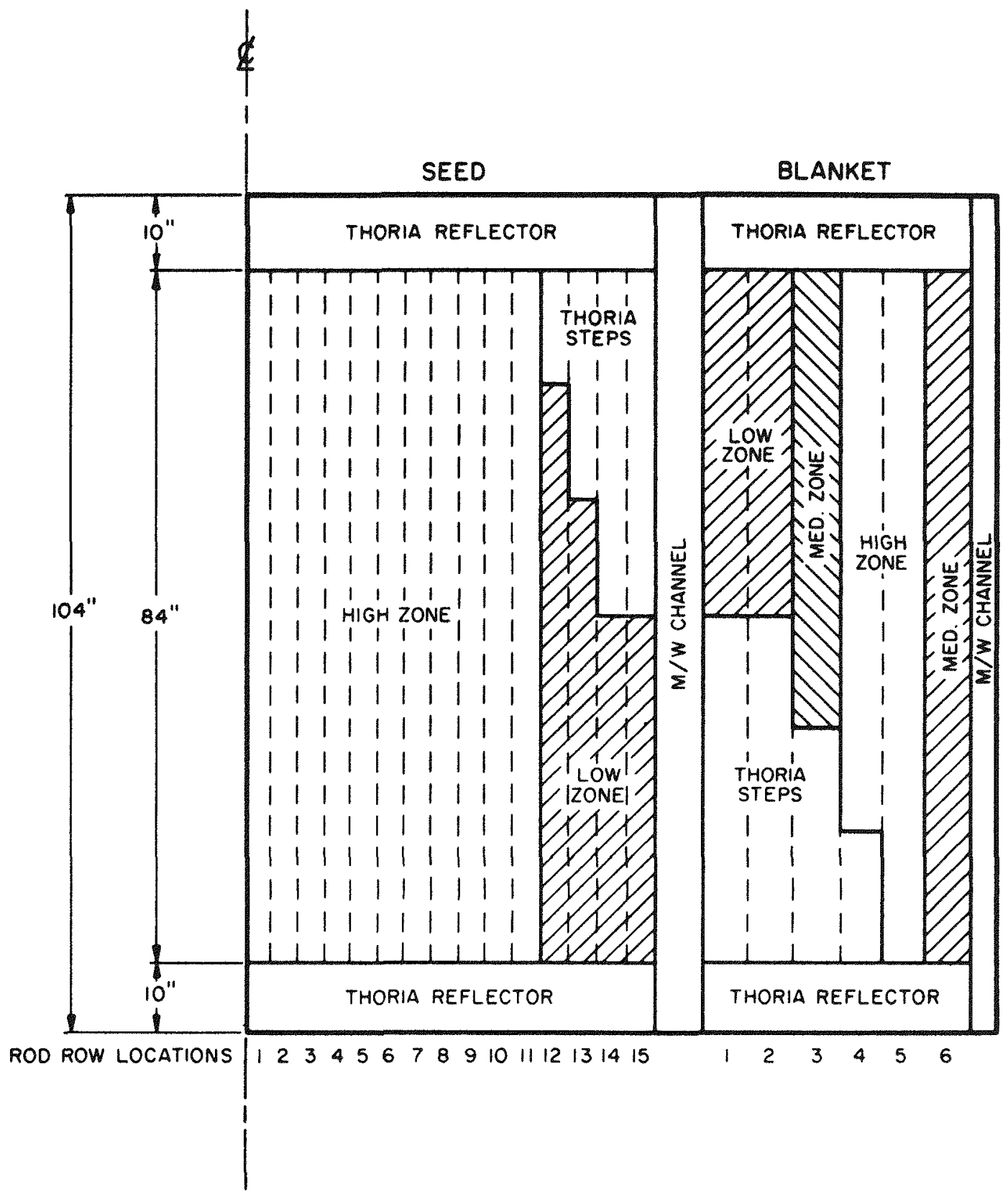

FIGURE 15 .

RZ Schematic of an LWBR Module 
separate the U-233 bearing materials in the seed and blanket and the reactivity is lowered. Conversely, raising the seed decreases the absorption in thorium and increases reactivity.

The stepped shape of the thoria regions increases the amount of reactivity control generated by moving the seed. The control achieved by this fuel distribution is largest for low positions of the seed (relative to the seed-blanket aligned position) and smallest for high positions of the movable seed. The variable geometry reactivity control has been designed so that throughout the entire range of operating positions, lowering fuel will lower reactivity and raising fue 1 will increase reactivity.

When the reactor is shutdown, the seed assemblies are below the rest of the fuel in the core as shown in Figure 14. For LWBR this displacement is five feet. To start up the reactor, the operator raises the seed assemblies in a uniform bank. By moving the seed fuel assemblies up, more nearly into alignment with the rest of the core, the operator brings the uranium-233 bearing parts of the fuel closer together. At the beginning of core life, hot critical operation occurs with the tops of the seed assemblies about 2 feet lower than the top of the stationary blanket assemblies. As the core operates and fission products accumulate, the seed assemblies are moved gradually upward toward a position about 2 feet higher than the blanket assemblies at the end of core life.

The variable geometry control system of LWBR minimizes but does not eliminate neutron loss for reactivity control. Calculated neutron absorption fractions in structure and water above and below the fuel regions in LWBR are shown in Figure 16. Early in core life, when the seed fuel assemblies are displaced downward by about 24 inches, the neutron absorption above and below the fuel is about $1 / 2$ percent. However, through most of core lifetime the neutron absorption above and below the fuel is less than 1/4 percent. As stated above, conventional LWR system control rods and soluble boron control consume about 4 percent of the neutrons.

From an operating point of view the variable geometry control system is similar in many respects to that of the movable poison rod control system used in many light water reactors. In the LWBR a buffer system prevents high contact 


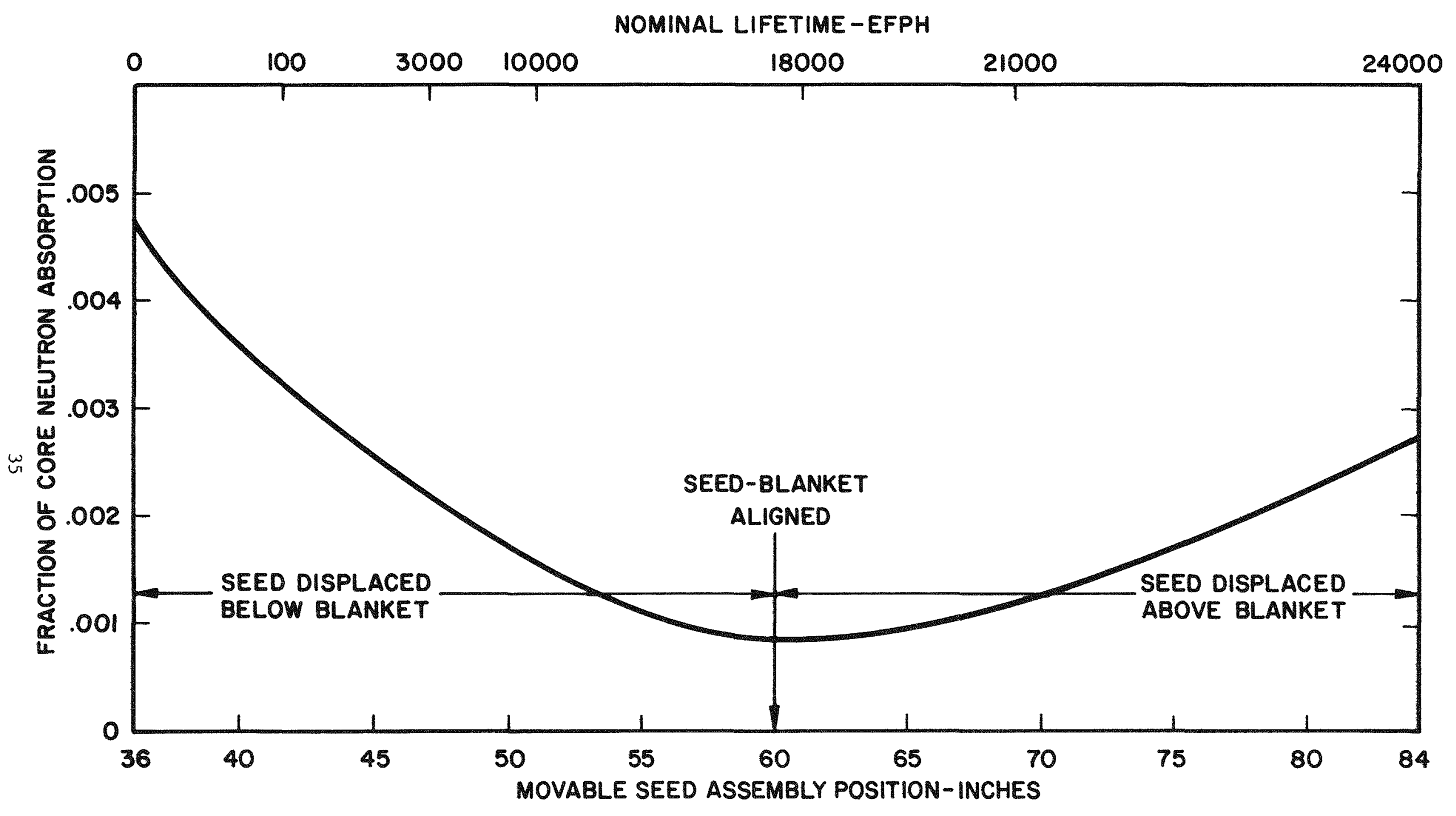

FIGURE 16.

Neutron Absorption Above and Below Fue1 
velocity as the movable seed assembly falls during a scram. Also, to counteract the upward hydraulic force on each movable seed assembly, a small fraction (approximately 2 percent) of inlet coolant is piped to the top of the core and then passed downward across a balance piston resulting in a net downward force on each module. More comprehensive descriptions of these LWBR systems are given in Reference 1.

\section{B. Use of Peripheral Reflector Regions}

Another major loss of neutrons in current LWR systems is loss from the periphery of the core to reactor vessel internal structures and water. $A$ large part of this 4 percent loss (Reference 2) can be reduced through use of peripheral reflector regions.

The LWBR core has both a radial and axial thorium oxide reflector region. The axial reflector consists of a 10 inch thoria region placed at the top and bottom of the fuel rods, as shown in Figure 15, to reduce neutron leakage from the fuel regions that initially contain uranium-233. As discussed above in Section III-A and shown in Figure 16, the calculated neutron absorption in structure and water above and below the fuel is less than $1 / 4$ percent through most of LWBR core lifetime.

The radial reflector in the Shippingport LWBR core is an annular region, about 9 inches thick, which surrounds the central power producing fuel modules as shown in Figure 13. This radial reflector region consists of large diameter ( 0.832 inch) fuel rods containing thorium oxide fuel pellets. To minimize neutron absorptions in water, a tight triangular rod spacing (rod center to center $=0.900 \mathrm{inch}$ ) was used such that the metal/water volume ratio is about 3.5 in this reflector region.

Calculated neutron absorption fractions in the radial reflector plus the metal/water radially outward from the radial reflector region for the LWBR core are shown in Figure 17. The total neutron absorption in these exterior regions averages approximately 8 percent but, as shown in Figure 17 , about 6 percent of the total core absorption is in the fertile material (thoria) of the reflector region. Since neutron capture in the thoria 


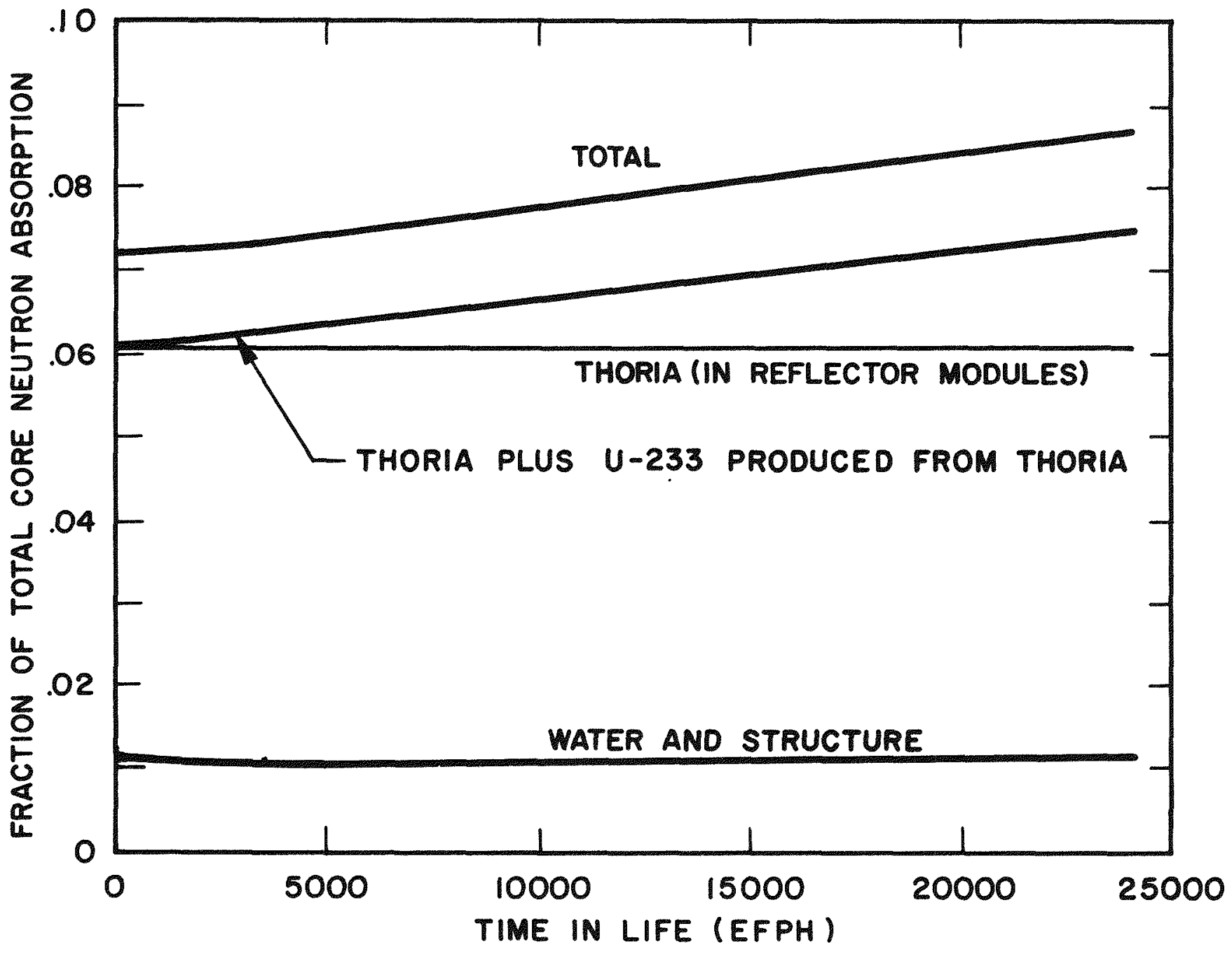

FIGURE 17.

Neutron Absorption External to the Twelve

Central Modules in the Shippingport LWBR Core 
reflector fuel produces uranium-233, these neutron absorptions are not neutron losses, and the increasing absorption in the uranium-233 produced is shown. The actual radial neutron losses are those absorbed in the water and structure both within the radial reflector region and exterior to the reflector. For the Shippingport LWBR core this radial neutron loss is about 1.2 percent, as shown in Figure 17. In a very large LWBR, this loss would be even smaller.

\section{Low Hafnium Zirconium Alloy for Fuel Element Cladding and Structurals}

The use of Zircaloy rather than stainless steel as a cladding and structural material is a crucial contributor to breeding in a light water reactor. The common use of Zircaloy in the nuclear industry was an outgrowth of development work of the Naval Reactors program prior to the LWBR program (Reference 5).

In the late 1940's, the leading candidate materials for fuel cladding were stainless steel and aluminum. For power reactors, the use of aluminum is not promising because of its poor high-temperature properties. Thus, stainless steel was assumed in many studies. Stainless steel has a significant cross section for capturing thermal and intermediate energy neutrons. It therefore acts as a poison (neutron absorber) causing many neutrons to be "lost" rather than to be used to produce new fuel and enhance breeding.

Zirconium was not seriously considered as a cladding material in these early studies because of its apparent high neutron absorption. However, at Oak Ridge National Laboratory it was discovered that the neutron poisoning in natural zirconium was due to 2 or 3 percent of hafnium that was present, and the zirconium itself absorbs relatively few neutrons. Practical production processes were developed for removal of hafnium and other impurities, and high-performance zirconium al loys were then developed. Both of these developments resulted from the Naval Reactors program, which introduced the practical use of Zircaloy, a highly corrosion-resistant and low-neutronabsorbing material for fuel cladding (Reference 5). 
The LWBR core contains many components fabricated of Zircaloy material including fuel rod cladding, full length shells between seed and blanket assemblies, and the support posts used for fuel rod grid attachments. Fuel rod cladding specifications for LWBR limited the hafnium content to a maximum of $40 \mathrm{ppm}$ (parts per million parts of Zircaloy by weight) and an average of $35 \mathrm{ppm}$. Certification data indicates that the final hafnium content averaged over all LWBR fuel rod cladding is $29 \mathrm{ppm}$.

Many out-of-pile material properties programs have been conducted on low hafnium material and extensive data are presented in Reference 6. Irradiation tests of both low and high hafnium Zircaloy material ( $<50 \mathrm{ppm}$ compared to 50 to $100 \mathrm{ppm}$ ) have been conducted with no apparent difference in tubing response attributable to hafnium content.

Neutron economy was al so improved in the LWBR core by minimizing the volume of Zircaloy. This was achieved by reducing the cladding thickness on all fuel rods in blanket regions to the point where the cladding must be supported by the fuel pellets. The LWBR fuel rod cladding has a diameter/thickness $(0 / t)$ ratio of about 20 in all blanket regions. Typical LWR cores have a $D / T$ ratio of about 16 . The LWBR seed rods on the other hand have a value of $D / t$ of 13.9 .

\section{Use of Close Fuel Rod Spacing}

The rod lattice of the LWBR core is closely spaced in order to minimize neutron losses by capture in water and increase neutron captures in the thorium atoms to enhance conversion to uranium-233. This is especially true in the regular blanket, which is a region of high breeding gain, where the metal/water volume ratio $(M / W)$ is 3.0. The core is designed to maximize neutron economy and thus significant thoria conversion al so occurs in the seed and the power flattening blanket. However to enhance thermal fissioning of $U-233$ in these regions, wetter lattices are employed $(M / W=1.72$ for seed, 1.75 for the power flattening blanket). A typical commercial PWR lattice has a 0.82 metal/water ratio.

There are actually several effects on neutron economy and fuel utilization due to the closely spaced LWBR fuel lattice and the resulting neutron distribution which has more neutrons at intermediate and higher energies than 
current commercial LWR's. In a reactor with a closely spaced fuel lattice a relatively large fraction of the neutrons absorbed in uranium-233 are of intermediate energy*, implying a rather low value of $n$ : that is, a value between the 2.13 for intermediate energy neutrons and the 2.3 which applies to thermal neutrons (see Figure 1). However, there are additional effects which take place when the neutron energy spectrum is shifted from thermal toward the intermediate and higher energy range. Additional neutrons are produced, both by fast fission in thorium and by $(n, 2 n)$ reactions, so that the effective value of $n$ is greater while the neutron losses by absorption in water and other parasitic reactions are significantiy reduced. Parasitic absorption is reduced because the absorption cross sections for all structural metals in the core, as we11 as the major fission product absorbers (xenon and samarium), are smaller for higher energy neutrons than for thermal neutrons. This design approach, i.e., balancing the reduced neutron losses in dry lattices against the reduced magnitude of $n$, is one of the important developments that has led to breeding in the LWBR. The use of a closely spaced fuel lattice required engineering development in fuel element, thermal-hydraulic, and structural areas (Reference 1).

\section{E. Fuel Rod Support Grid System}

Projected neutron absorption by the fuel rod support grid system was also closely controlled for the Shippingport LWBR core. Zircaloy grid spring relaxation during irradiation was a major concern at the time the LWBR grid was developed. A stainless steel grid material, which has better relaxation properties than other candidate grid materials such as Inconel or Zircaloy, was used in the Shippingport LWBR. The choice of AM-350 stainless steel for the grid material was based on good relaxation properties but it also has a relatively low aggregate neutron absorption cross section compared to Inconel. For example, stainiess steel304 has an aggregate neutron absorption cross section about 8 percent greater than AM-350, due primarily to the higher nickel and manganese content in SS-304. Optimizing breeding requires minimizing parasitic neutron losses. This need provided the basis for a comprehensive technological development program to assure

* The term "intermediate energy neutrons" here may be thought of as covering a range from near 1 ev to several thousand ev. Thermal neutrons average about $1 / 20$ ev in a reactor. 
an adequate but not excessive rod support grid design. Following extensive full size grid tests and analysis it was determined that the grid material thickness could be reduced from the original specifications. The seed region grid thickness was reduced from 14 to $13.5 \mathrm{mils}$ ( 3.6 percent) and the blanket region grid thickness was reduced from 15 to $14 \mathrm{mils}$ (6.7 percent).

IV. FUTURE IMPROVEMENTS IN NEUTRON CONSERVATION TECHNOLOGY

Improved fuel utilization efficiency can be achieved by increasing fuel burnup so long as breeding is maintained. This is illustrated in the following general formula for fuel utilization efficiency. Consider a fuel loading cycle, i.e., a period of time between reactor refuelings; for any such cycle

$\begin{aligned} & \text { Fuel Util. } \\ & \text { Efficiency }\end{aligned}=\frac{\text { fuel fissioned }}{\text { fuel fissioned }+ \text { reproc. losses }+ \text { fuel makeup }}=\frac{\begin{array}{l}\text { energy obtained } \\ \text { from the reactor }\end{array}}{\begin{array}{l}\text { energy potentially } \\ \text { avail. from the fuel }\end{array}}$

This may be written in terms of fractions of the beginning-of-cycle fuel loading as

$$
\begin{aligned}
& \text { FUE }=\frac{\% \text { burnup }}{\% \text { burnup }+\% \text { losses }+\% \text { makeup }} \\
& \% \text { burnup }=\frac{\text { number of heavy a toms fissioned }}{\text { number of heavy atons present at beginning of life }} \\
& \text { FUE }=\frac{1}{1+\frac{\% \text { losses }}{\% \text { burnup }}+\frac{\% \text { makeup }}{\% \text { burnup }}} \\
& \text { If the end-of-cycle Fissile Inventory Ratio (FIR) is high enough to offset the } \\
& \text { fractional loss to spent core recycling (i.e., reprocessing and } \\
& \text { refabrication), then the fuel makeup required is zero and the reactor is said } \\
& \text { to be breeding. In that case the greater the fraction of fuel fissioned per }
\end{aligned}
$$


cycle, the better will be the fuel utilization. That is to say, when a breeder cycle is attained, where FIR $\geq 1+$ fractional losses, there is no makeup required and the fuel utilization from that time on is determined by the reprocessing losses and the burnup per cycle.

Increasing the power density in the core would cause a reduction in FIR due to increased concentrations of xenon and protactinium-233. Longer fuel burnup would result in larger fission product concentrations and cause a reduction in FIR. Thus, if breeding is to be achieved, any increase in power density or increase in burnup would require design changes to improve FIR to offset the added losses.

In addition, design features to improve FIR would be needed to make up for reductions in FIR which arise through the change in the isotopic composition of recycled uranium. Initial uranium loading in the LWBR core at Shippingport contained over 98 percent $U-233$ and less than 0.1 percent $U-235$ and U-236. In subsequent fuel cycles, using recycled fuel, the fraction of $U$ 235 and U-236 would be increased. Eventually an equilibrium distribution of uranium isotopes would be achieved. An increase in the U-235/U-233 ratio would cause a reduction in FIR because of the lower eta for U-235, as discussed in section II.A. Larger neutron absorption by U-236 would al so reduce the FIR.

Features which could be included in future light water reactor designs to further improve neutron conservation and enhance breeding are presented in the following sections. Development of these concepts is continuing in the Advanced Water Breeder Applications (AWBA) program.

\section{A. Further Development of Neutron Economic Reactivity Control}

Variable geometry reactivity control in the LWBR made a large improvement in fuel utilization by elimination of poison control rods or soluble boron control. Two features desired for improving performance of light water breeders are reduced nuclear peaking factors and reduced structural neutron absorption. One means of achieving these is to use a 
movable finger control concept which could combine the movable poison finger concept of present commercial reactors with neutron economic control presently used in the Shippingport LWBR core.

Movable finger control could use two types of movable rods in the fuel lattice rather than moving an entire fuel assembly as in the Shippingport LWBR core. Poison finger rods would provide accident shutdown capability and could be withdrawn from the core prior to operation of the plant at power. Thoria fuel finger rods of various lengths could be used for reactivity control during normal reactor power operations. This concept is being developed under the AWBA program to determine if it is practical for a power reactor.

High local power peaks in the LWBR arise from the necessity for the stepped fuel arrangement used to obtain reactivity control. The finger control concept would disperse the movable fuel elements throughout the fuel assembly. A fuel assembly designed with the finger control concept could improve fuel utilization by eliminating the need for the large hydraulic isolation and support shells found in the Shippingport LWBR core design. As in commercial LWR's, the finger rods would travel wi thin vertical guide tubes which would provide structural support for the fuel rod grids. This concept would require less structural material and thus enhance breeding compared to the Shippingport LWBR core design.

Neutron absorption in water and structure above and below the fuel would also be reduced for the finger control design. LWBR fuel module displacements from the seed-blanket aligned position cause increased neutron absorption in axial water and structure, shown in Figure 16. These increased axial neutron losses would not occur in a finger controi design core. However, some neutron absorption occurs in water entering the core to fill the space vacated by withdrawing the finger control rods.

\section{B. Use of Zircaloy Rod Support Grids}

Stainless steel (AM-350) grids for fuel rod support in the 
Shippingport LWBR core consume approximately 0.6 percent of the neutrons. For the LWBR spectrum of neutron energies, AM-350 neutron absorption is estimated to be about ten times as great as in an equal volume of Zircaloy.

Zircaloy grids are presently used in some commercial reactors. The strength of Zircaloy alloys is less than the strength of stainless steel so the required grid 1igament thickness is greater than for an AM-350 steel grid. A Zircaloy grid fuel rod support system would therefore probably require a larger total grid volume than an AM-350 grid system. However, since Zircaloy neutron absorption is about one-tenth that for AM-350, the total grid neutron absorption would be much smaller for Zircaloy grids.

Using Zircaloy grids instead of AM-350 could increase the FIR for an LWBR by about 0.005 . Zircaloy fuel rod support systems are being developed in the AWBA program.

\section{Fuel Element Design Modifications}

The movable finger control concept discussed in Section IV-A / if feasible) could lead to lower power peaking factors than in the Shippingport LWBR core. Further reduction in fuel temperature could be achieved by using a duplex fuel pellet design. Duplex pellets could consist of a $\mathrm{ThO}_{2}$ core inside of. a $\mathrm{UO}_{2}$ annulus. The diameter of seed rods could then be increased over those used in the Shippingport LWBR core.

The diameter/clad thickness ratio is 13.9 for the Shippingport LWBR core seed rods. For the three blanket rod types in the LWBR the diameter/clad thickness ratio is about 20. Increasing the seed rod diameter but using a clad thickness to achieve a diameter/thickness ratio of 20 would reduce the Zircaloy rod cladding volume. A higher diameter/thickness ratio with self-standing clad could be achieved by means of pressurized fuel rods. An increase in seed rod diameter/thickness from 13.9 to 20 would reduce neutron absorption in seed rod cladding by about 28 percent and provide an increase in FIR. 


\section{Use of Fuel Management}

Fuel management techniques are generally used in large commercial reactors. Only part of the fuel is replaced at each refueling and the remaining fuel is cycled to new locations within the core. The present Shippingport LWBR core is much smaller than the core in a large central station commercial reactor plant. An effective diameter for the 12 module power producing region of the LWBR core is about 68 inches compared to about 150 inches for current commercial cores. The fuel utilization and FIR predicted for the present LWBR core is based on a single fuel loading for the entire core lifetime.

There are several potential advantages to the fuel management cycling and refueling techniques used in large commercial reactors. Reduction in local power peaks may be achieved by cycling partially depleted fuel into regions where new fuel would result in higher power peaks. Excess core reactivity may be smaller following a partial refueling so that less reactivity control is required.

In a fuel managed commercial reactor a special power flattening blanket region with increased reactivity might not be necessary. The fuel management process itself would serve to flatten the radial power distribution. The outer fuel region could then be drier than in the Shippingport LWBR corre and breeding would be enhanced.

Another possible advantage for fuel management is that the fuel exposure time in the core might be increased. An increase in the fuel exposure time in the core could reduce the time averaged recycle losses and improve fuel utilization so long as the core continues to breed. Application of fuel management techniques in large commercial LWBR cores could therefore improve the overall fuel utilization relative to the present LWBR core. These advantages would have to be weighed against the potential advantage of not having to open the reactor for servicing for 3 to 4 years which the Shippingport LWBR core enjoys. 


\section{CONCLUSIONS}

The LWBR core presently operating in the Shippingport Atomic Power Station is expected to confirm that breeding can be achieved in a light water reactor system. A best estimate calculated core FIR is in the range 1.013 to 1.016 , depending on the power operation history.

Two key aspects of the LWBR core design which make breeding possible are the fuel used and neutron conservation techniques. The fissile fuel $U-233$ is required since it provides the largest number of neutrons produced per atom of fissile fuel destroyed. In addition, the use of thorium as a fertile material will demonstrate advantages which could be exploited even in reactor systems where breeding is not achieved. The primary advantage is that U-233 is produced by neutron absorption in thorium. Using thorium as a fertile material also provides a way to utilize the abundant thorium resources as a source of energy and to reduce the use of uranium reserves.

Design features implemented in the LWBR core to reduce neutron losses and thus improve fuel utilization have been described. Use of these neutron conservation methods in current 1 ight water reactor designs would provide a substantial increase in the energy extracted from each unit of mined ore.

Several additional features which could be included in future extensions of the LWBR core concept to larger commercial reactors have al so been discussed. An increase in breeding ratio from such features could likely be used to permit high power density and greater fuel burnup thereby potentially achieving even better fuel utilization than would be possible with the Shippingport LWBR core concept.

\section{ACKNOWLEGEMENTS}

The design and development of the LWBR core at the Bettis Atomic Power Laboratory evolved through the efforts of a large group of engineers and scientists over a period of more than a decade. 


\section{REFERENCES}

1. D.R. Connors, S. Milani, J.A. Fest, and R. Atherton, editors, "Design of the Shippingport Light Water Breeder Reactor", WAPD-TM-1208, January, 1979.

2. D.S. Rampolla, et al, "Fuel Utilization Potential in Light Water Reactors with Once-Through Fuel Irradiation," WAPD-TM-1371, July 1979.

3. S.R. Taylor, "Abundance of Chemical Elements in the Continential Crust, A New Table", Geochem. Cosmochem. Acts 28, 1273-1285 (1964).

4. H.C. Hecker, Jr. "Summary of the Nuclear Design and Performance of the Light Water Breeder Reactor (LWBR)", WAPD-TM-1326, June 1979.

5. B. Lustman, "History and Development of Zirconium Alloys for Use in Nuclear Reactors", TID-26740, March 21, 1975. A7so, B. Lustman and F. Kerze,Eds., "Metallurgy of Zirconium", McGraw Hill, New York, 1955.

6. C.R. Woods, Editor, "Properties of Zircaloy-4 Tubing", WAPD-TM-585, December 1966. 